\title{
A spatially explicit optimization model for the selection of sustainable transport technologies at regional bus companies
}

\author{
Damiana Chinese ${ }^{1} \cdot$ Piero Pinamonti $^{1} \cdot$ Caterina Mauro $^{1}$
}

Received: 16 November 2020 / Revised: 5 May 2021 / Accepted: 6 May 2021 /

Published online: 1 June 2021

(c) The Author(s) 2021

\begin{abstract}
Buses account for almost $60 \%$ of the total public transport services in Europe, and most of the vehicles are diesel fuelled. Regional transport administrators, under pressure by governments to introduce zero-emission buses, require analytical tools for identifying optimal solutions. In literature, few models combine location analysis, least cost planning, and emission assessment, taking into account multiple technologies which might achieve emission reduction goals. In this paper, an existing optimal location model for electric urban transport is adapted to match the needs of regional transport. The model, which aims to evaluate well-to-wheel carbon emissions as well as airborne emissions of $\mathrm{NO}_{\mathrm{x}}$ and PM10, is applied to a real case study of a regional bus transport service in North Eastern Italy. The optimization has identified electric buses with relatively small $(60 \mathrm{kWh})$ batteries as the best compromise for reducing carbon equivalent emissions; however, under current economic conditions in Italy, the life cycle cost of such vehicles is still much higher than those of Euro VI diesel buses. In this context, our model helps in identifying ways to minimize infrastructure costs and to efficiently allocate expensive resources such as electric buses to the routes where the maximum environmental benefit can be achieved.
\end{abstract}

Keywords Bus transport · Electric buses $\cdot$ CNG buses $\cdot$ Recharging infrastructure . Location analysis $\cdot$ Extended well-to-wheel analysis

\section{Abbreviations}

$\begin{array}{ll}\text { BAU } & \text { Business as usual } \\ \text { BE } & \text { Battery electric } \\ \text { BEV } & \text { Battery electric vehicle } \\ \text { CNG } & \text { Compressed natural gas } \\ \text { FAME } & \text { Fatty acid methil esters }\end{array}$

Damiana Chinese

damiana.chinese@uniud.it

1 DPIA - Dipartimento Politecnico di Ingegneria e Architettura, University of Udine, Udine, Italy 


$\begin{array}{ll}\text { GHG } & \text { Greenhouse gases } \\ \text { GWP } & \text { Global warming potential (over } 100 \text { years) } \\ \text { HP } & \text { High pressure (40 bar gas pipeline) } \\ \text { LP } & \text { Low pressure (4 bar gas pipeline) } \\ \text { LCA } & \text { Life cycle assessment } \\ \text { NO }_{x} & \text { Nitrogen oxides relevant for air pollution } \\ \text { PM10 } & \text { Particulate matter } 10 \mu \mathrm{m} \text { or less in diameter } \\ \text { SCR } & \text { Selective catalytic reduction } \\ \text { TTW } & \text { Tank to wheels } \\ \text { WTT } & \text { Well to tank } \\ \text { WTW } & \text { Well to wheels } \\ \text { ZEB } & \text { Zero emission bus }\end{array}$

\section{Indices}

Bus route

$S$

$t$

$e l$

cng

Bus stop

Bus technology (diesel, CNG, BEV $60 \mathrm{kWh}, \mathrm{BEV} 120 \mathrm{kWh}$ )

Subset of $\mathrm{t}$ including BEV $60 \mathrm{kWh}$ and BEW $120 \mathrm{kWh}$ only

Subset of $t$ including CNG technology only

\section{Variables}

$\delta 1, \delta 2, \delta 3(s, e l) \quad[0,1]$ Variables to determine the total number of charging stations to be installed at stop s (binary)

$\gamma_{1}, \gamma_{2}, \gamma_{k}(s, e l) \quad[0,1]$ Variable, work as flag to classify the number of routes needing recharging at stop $\mathrm{s}(0,1$,between 2 and $\mathrm{k}-1, \mathrm{k}$ or above) (binary)

$C_{t o t} \quad$ Annual equivalent total system cost (continuous)

$\mathrm{CO}_{2} e q_{T T W}(t) \quad$ Total annual equivalent $\mathrm{CO}_{2}$ emissions from Tank to Wheels (positive)

$\mathrm{CO}_{2} e q_{W T T}(t) \quad$ Total annual equivalent $\mathrm{CO}_{2}$ emissions from Well to Tank (positive)

$N B(l, t) \quad$ Number of buses of technology t assigned to route 1 (integer)

$N P(s, t) \quad$ Number of charging stations of technology t installed at stop $\mathrm{s}$ (integer)

TUS $(l, t) \quad[0,1]$ Variable, equals 1 if technology $\mathrm{t}$ is assigned to line 1 (binary)

$U S(l, s, t) \quad[0,1]$ Variable, equals 1 if charging of technology t for line 1 is required at stop s (binary)

\section{Parameters}

$\varepsilon$

$a$

bat $_{\text {cost }}$

$b_{\text {cost }}(t)$

$b_{\text {main }}(t)$
Fixed arbitrary small number

Annualization factor

Batteries capital cost coefficient ( $€ / \mathrm{kWh})$

Bus capital cost $(€)$

Bus maintenance annual cost $(€ / \mathrm{km})$ 


\begin{tabular}{|c|c|}
\hline$c(s)$ & $\begin{array}{l}{[0,1] \text { Scalar, is } 1 \text { if two or more trips from different routes are }} \\
\text { scheduled to stop at } s \text { at the same time }\end{array}$ \\
\hline $\operatorname{cap}_{\text {bat }}(\mathrm{el})$ & Battery storage capacity (kWh) \\
\hline $\mathrm{CO}_{2} e q_{T T W}(t)$ & Tank-to-Wheel carbon equivalent emission factor $(\mathrm{t} / \mathrm{km})$ \\
\hline $\mathrm{Co}_{2} e q_{W T T f u e l}(t)$ & $\begin{array}{l}\text { Well-to-Tank carbon equivalent emission factor for fuels or } \\
\text { energy supplied to vehicles }(\mathrm{t} / \mathrm{km})\end{array}$ \\
\hline $\mathrm{Co}_{2} e q_{W T T b a t t}(e l)$ & $\begin{array}{l}\text { Well-to-Tank carbon equivalent emission factor for manufactur- } \\
\text { ing of batteries, for BEV } 60 \mathrm{kWh} \text { and BEV } 120 \mathrm{kWh} \text { vehicles } \\
\text { only (t/unit) }\end{array}$ \\
\hline $\mathrm{CO}_{2} e q_{W T T s t a t}(t)$ & $\begin{array}{l}\text { Well-to-Tank carbon equivalent emission factor for manufactur- } \\
\text { ing of fuelling/charging stations ( } \mathrm{t} / \mathrm{unit} \text { ) }\end{array}$ \\
\hline $\operatorname{cons}(t)$ & Fuel economy $(\mathrm{kWh} / \mathrm{km})$ \\
\hline$D(l, s, s+1)$ & Distance between stop $\mathrm{s}$ and successive stop $\mathrm{s}+1$ on route $1(\mathrm{~km})$ \\
\hline durationbatt(el) & Expected lifetime of batteries (y) \\
\hline durationstat $(t)$ & Expected lifetime of charging station $(y)$ \\
\hline$d y$ & $\begin{array}{l}\text { Average total time available for bus operation, in days per year } \\
\text { (day/y) }\end{array}$ \\
\hline$f(t)$ & Fuel cost $(€ / \mathrm{kWh})$ \\
\hline$i$ & Interest rate \\
\hline$L_{\text {trip }}(l)$ & Route length (km) \\
\hline$M$ & Fixed arbitrary large number \\
\hline$n$ & Project life in years $(y)$ \\
\hline$n_{\text {trip }}(l)$ & Number of trips per day for each route \\
\hline$s_{\text {cost }}(t)$ & Charging/Fuelling station capital cost- $(€)$ \\
\hline$s_{\text {main }}(t)$ & Charging/Fuelling station annual O\&M cost (€/y) \\
\hline$S O C_{\min }$ & Minimum state of charge for batteries \\
\hline$t_{\text {charge }}(s, t)$ & Charging time allowed for each technology and stop (min) \\
\hline$t_{o p}$ & $\begin{array}{l}\text { Average total time available for bus operation, in minutes per } \\
\text { year }(\min / \mathrm{y})\end{array}$ \\
\hline$t_{\text {trip }}(l)$ & Travel duration on route 1 ( $\mathrm{min}$ \\
\hline
\end{tabular}

\section{Introduction}

In European urban areas, public transport accounts for $21 \%$ of the total number of motorised trips and is responsible for roughly $10 \%$ of transport related greenhouse gas (GHG) emissions (UITP 2018). According to the International Association of Public Transport, buses account for 50-60\% of the total public transport offer in Europe (UITP 2016) and, according to a recent survey (Corazza et al. 2016), 79\% of operational vehicles are diesel fuelled.

Despite the introduction of increasingly restrictive standards on diesel engine emissions, with Euro VI coming into force in 2014, diesel buses continue to make a substantial contribution to urban air pollution. Local governments are calling for the introduction of zero-emission buses (ZEB), which they often view as a means of reducing local air pollution problems, rather than specifically reducing carbon emissions (Bakker and Konings 2018). In fact, an international survey on local bus 
operators (Corazza et al. 2016) shows that more than $40 \%$ of the respondents would opt for increasing the use of electric vehicles, $28 \%$ would opt for change in favour of more compressed natural gas $(\mathrm{CNG})$, and $13 \%$ towards greater use of vehicles fuelled by bio-methane. Obviously, each of these choices has different economic and environmental implications, and some of them are not explicitly evaluated by local governments or by administrators, whose perceptions may fail to take into account all aspects of the real situation on the grounds (Corazza et al. 2016). To enable informed decision making for the future development of public transport systems, decision support tools may be of help, particularly when multiple technology options need to be given consideration, and when the transition to ZEB requires the development of appropriate but capital-cost-intensive charging infrastructure.

The present study was motivated by the requirement of an Italian regional bus transport company to evaluate the feasibility of improving its environmental performance by introducing alternative bus technologies, including battery electric vehicles, in the intercity regional bus transport network.

To compare different technology options, and particularly different powertrains, several approaches and indicators are adopted in literature, such as life cycle cost analysis (Hellgren 2007), fuel use and primary energy use (Gustafsson et al. 2018), real ecological impact (Esser et al. 2020), well-to-wheel (WTW) analysis (Wang 2002; Edwards et al. 2011), eco-efficiency (Lee et al. 2011) and life cycle assessment (Ercan and Tatari 2015).

The fuel cycle or WTW analysis is one of the earliest and most commonly applied methods to evaluate the environmental impact of alternative fuels and powertrains for buses (Correa et al., 2017). The WTW analysis of a vehicle/fuel system covers all stages of the fuel cycle-from energy feedstock recovery (wells) to making the fuel available at tanks (well-to-tank, WTT), and from the energy supplies which need to be available at fuelling-recharging stations, down to the energy delivered at vehicle wheels (tank-to-wheels, TTW).

However, WTW analyses generally does not account for the embodied energy and indirect carbon emissions associated with component manufacturing, particularly with regard to manufacturing batteries. More comprehensive and complex Life Cycle Assessment (LCA) approaches, which were recently reviewed by Harris et al. (2018) also account for additional stages such as the extraction and processing of raw material, for manufacturing, as well as for the decommissioning of the vehicles themselves. Such analyses predominantly focus on GHG emissions (Harris et al. 2018) while others present more comprehensive impact indicators (e.g. water withdrawal in Ercan and Tatari (2015), toxicity to humans, ionizing radiation, and depletion of minerals and fossil fuels in Petrauskiené et al., (2020)). In this context, a recent trend is the use of extended WTW models, which carefully incorporate LCA data into WTW analyses to account also for the impact of manufacturing and substitution of batteries and for estimating carbon footprint indicators (Moro and Helmers 2017). Some hybrid methods (Ercan and Tatari 2015) also account for the GHG emissions associated with additional infrastructure required for recharging or refuelling new fleets using alternative powertrains.

To obtain more comprehensive cost-benefit analyses, traditional or extended well-to-wheel analyses has usually been complemented by life cycle costing 
(Lajunen and Lipman 2016). The performance indicators calculated with these approaches are sometimes incorporated in more comprehensive frameworks, such as external cost frameworks (Mitropoulos et al. 2017), multi-criteria frameworks (Tzeng et al. 2005), fuzzy models (Büyüközkan et al. 2018; Adhami and Ahmad 2020), probabilistic models (Harris et al. 2020; Buakum and Wisittipanich 2020), and optimization approaches (Durango-Cohen and McKenzie 2018). Among the latter, Durango-Cohen and McKenzie, (2018) performed a fleet optimization considering different fuels, hybrid electric and hydrogen fuel cells as options to minimize total cost of ownership, on one hand, and lifecycle $\mathrm{NO}_{\mathrm{x}}$ emissions, on the other hand. As observed in Harris et al. (2020) in most cost-benefit analyses individual routes or driving cycles are taken as reference (see e.g. Mitropoulos et al. 2017; Tzeng et al. 2005); often, also one reference vehicle at time is considered. Harris et al. (2020) observe that "when comparing new technologies, a common misleading assumption is that new bus fleets are a like-for-like replacement, regardless of their technological capabilities or route specific energy demands". In some cases, as in Durango-Cohen and McKenzie (2018), entire fleets are considered, rather than a single individual reference vehicle, but it is assumed that fuelling issues, including cost and impacts of fuelling infrastructure, do not affect the issues of re-fleeting. We agree that this is certainly true for traditional fuels, or more precisely those fuels and technologies compatible with existing fuelling stations, such as biodiesel. However, this may not be the case for alternative fuels and powertrains, e.g. CNG and electric vehicles, which require bus companies to install dedicated, capital intensive infrastructure.

Based on the literature we examined, as well as on the needs of companies and public authorities, the present study introduces an optimization model aimed at minimizing the life cycle costs of bus fleets while simultaneously meeting emission reduction constraints. In line with Harris et al. (2020) and Ercan and Tatari (2015), we argue that recharging issues must be considered in cost-benefits analyses and handled at a fleet level, particularly for battery electric buses, costs which were not examined in Durango-Cohen and McKenzie (2018). In fact, for electric buses, and for electric vehicles in general, challenges to installing newcapital intensive charging infrastructure are exacerbated by several factors, including:

- The high specific costs of batteries and their limited capacities;

- Range anxiety, which in the business context of intercity bus transport should be understood as technical anxiety (Noel et al. 2019) that is, the purchaser's concern that real-world mileage range between charges will be significantly lower than expected, and that vehicles won't be able to complete their scheduled runs;

- Uncertainty about the cost effectiveness of alternative or complementary charging technologies (e.g. inductive, conductive, battery swapping) (Chen et al. 2018).

Notwithstanding these barriers, a rapid development of battery electric vehicles and an increasing maturity of fast charging technologies is envisioned in the near future (Pereirinha et al. 2018). Hence, a large body of engineering literature has been devoted to optimizing the location and capacity of battery charging infrastructure, 
particularly aimed at serving commercial battery electric vehicles (BEVs) such as buses. For further reference note Shen et al. (2019) for a recent comprehensive review of BEVs in general, and He et al. (2019) for a recent review with a focus on electric buses.

From the reviews we examined, it can be inferred that most infrastructure optimization models aim at deploying systems so that total costs are minimized. Such models are generally focused on electric technologies alone. This is e.g. the case of Islam and Lownes (2019), who optimize a course of fleet replacement and recharging infrastructure purchase over the years. They account for the costs of both bus fleets and recharging stations, but they assume that recharging is entirely performed at depot chargers on a one-on-one basis. They do not account for spatial issues in planning recharging stations. A spatially explicit approach is taken by Rogge et al. (2018), who also focus on electric technologies alone and use genetic algorithms to optimize at the same time the composition, the recharging schedule and infrastructure of an electric bus fleet. They minimize total costs of ownerships but do not account for environmental impact. Indeed, only few optimization models (Nie et al. 2016; Xylia et al. 2017) take environmental impact, in particular emissions, into account at the same time, to enable a spatially explicit cost-benefit planning of fleet and infrastructure. To the best of the authors' knowledge, very few models consider both traditional and electric technologies at the same time. Su et al. (2019) take diesel, CNG, and electric buses into consideration when using a continuous approximation approach to optimize the design of an assigned bus route in a Chinese city. Their model is focused on a single corridor and addresses bus stop spacing, service headway, and speed. It should be observed that the model by Su et al. (2019) examines each vehicle type individually: the optimization of the fleet composition is not part of the model itself. The model developed by Xylia et al. (2017) has the unique feature of optimizing the allocation and use of both electric bus technologies and of traditional, internal combustion engine buses fuelled with alternative fuels, on different routes within the same network. This model was applied to the development of the electric buses in the city of Stockholm, particularly the inner city zone (Xylia et al., 2019). Xylia's model is oriented to urban bus transport, which was the case with the electric bus network development models we examined. Several models involving practical case studies on real bus networks were for German settings (Sinhuber et al. 2012; Rogge et al. 2015,2018; Kunith et al. 2017). One (Wang et al. 2017) is for the USA.

As the intercity bus service considered in this study was undertaken within a relatively small province with low population density, travel distances may be comparable with urban problems in larger cities. However, the distance between stops is relatively farther than in urban settings, and the number of daily trips may be quite variable depending on route. These factors may make optimising infrastructure development more challenging. The aim of our model was therefore to identify in which routes and under which specific circumstances electrification could be viable, and how this would affect the composition and costs of the fleet for the regional bus company under examination. For this purpose, the mixed integer linear programming model presented by Xylia et al. (2017) seemed the most promising, although it required adapting to the features of regional bus transport, and to the technologies 
and emission settings typical to this part of Italy, at the same time as taking a fleet optimization perspective. How this aspect was carried out is discussed in the methodology (Sect. 2), which also addresses the environmental assessment framework developed here. The case study, data, and scenarios definition are presented in more detail in Sect. 3, which is followed by the discussion of the results in Sect. 4.

\section{Methodology}

In view of the concrete aim of this study, our objective was to consider immediate options available to regional bus companies rather than technologies which may available in the longer term. Hence, as we are discussing in Sect. 2.1, we have focused on fuels and vehicle types generally considered as a valid purchasing option by bus company administrators nowadays. Taking the fleet optimization approach recommended by Harris et al. (2020), the equations presented in Sect. 2.2. Have been added to the model proposed in Xylia et al. (2017). To meet environmental impact targets, the constraints presented in Sect. 2.3 have been introduced.

\subsection{Identification of context specific requirements}

Unlike Xylia et al. (2017), who focussed on a Scandinavian context aimed at $100 \%$ carbon emission abatement using $100 \%$ biodiesel as a fuel for conventional engines in combination with battery electric vehicles powered by a Nordic electric mix, we decided to set emission reduction targets at $50 \%$ for both GHG and air pollutants. Since public transport serves as a role model with respect to other transport companies, the chosen target is slightly more ambitious than carbon emission reduction targets for this kind of fleets in Italy. In fact, according to Transport and Environment (2019), in 2030 carbon emissions from heavy duty vehicles should be reduced by $45 \%$ compared to a 2015 baseline.

Focusing on fuels commonly used to date in regional bus companies in Italy (Camerano et al. 2017), fossil fuel based options such as diesel fuel and compressed natural gas $(\mathrm{CNG})$ have been examined.

An immediate option is the purchase of new buses with the most recent conventional technology (Diesel Euro VI). The current diesel mix entails a 9\% mandatory biofuel quota on the overall market, but a blending wall of $7 \%$ biodiesel was considered here as a maximum proportion of FAME (Fatty Acid Methil Esters) in conventional diesel (Nylund and Koponen 2012). It was decided not to consider higher shares of biodiesel as feasible options in the mid-term, given the technical limitations and concerns about engine performance and duration reported in Patel et al. (2016). Additionally, there are substantial concerns about actual biodiesel emission factors discussed in literature (Nylund and Koponen 2012), especially if one considers the impact of induced land use change due to the cultivation of crops for biofuel (Kampman et al. 2013).

CNG as a vehicle fuel generally boasts a high market penetration in Italy (Patrizio and Chinese 2016) and has been largely used at urban level by municipal 
bus transport companies for more than twenty years (Mercuri et al. 2002), with the main aim of reducing local pollutant emissions. CNG is thus considered as a valid short term option by company managers and local authorities owing to the long held belief that natural gas is a "clean" fuel, and also in view of potential conversion to bio-methane. Nevertheless, the current use of CNG in inter-urban transport is minimal (Camerano et al. 2017), primarily because of concerns about driving ranges.

Many authors in Europe (Logan et al. 2020), South America (Correa et al. 2017) and Asia (Khandekar et al. 2018) have called for a massive uptake of battery electric buses, and refer to them as the most interesting alternative for public transport decarbonisation, at least for trip ranges below $100 \mathrm{~km}$ (Correa et al. 2017). Given the geographic morphology of Italy and the way local bus company are organized in Italy, such trip ranges are in line with the requirements of regional inter-urban transport. However, additional recharging stations across the network are more likely to be required than in urban settings. The same holds true for CNG vehicles. For BEVs, the key research question for intercity transport is to evaluate whether superfast charging and smaller volume energy storage with numerous charging stations along the networks are preferable to larger energy storage in vehicles requiring fewer charging cycles (Nylund and Koponen 2012). For this reason, fully electric buses with either a $60 \mathrm{kWh}$ battery or a $120 \mathrm{kWh}$ battery have been considered as alternative options.

\subsection{Location and capacity optimization model}

As in Xylia et al. (2017), the objective function of the model is to minimize annualized system costs. In our version of the model, costs are expressed by Eq. 1:

$$
\begin{aligned}
\operatorname{MinC}_{\text {tot }}= & \sum_{s} \sum_{t}\left(s_{\cos t}(t) \cdot a+s_{\text {main }}(t)\right) \cdot N P(s, t)+\sum_{l} \sum_{t} b_{\cos t}(t) \cdot N B(l, t) \cdot a \\
& +\sum_{l} \sum_{t}\left(f(t) \cdot \operatorname{const}(t)+b_{\text {main }}(t)\right) \cdot L_{\text {trip }}(l) \cdot n_{\text {trip }}(l) \cdot d y+\operatorname{TUS}(l, t) \\
& +\sum_{l} \sum_{e l} b a t_{\cos t} \cdot \operatorname{cap}_{\text {bat }}(e l) \cdot N B(l, e l) \cdot n \cdot a
\end{aligned}
$$

Integer decision variables are the number $N P$ of charging or refuelling stations to be located at bus stop $s$ serving technology $t$, and the number of buses $N B$ with propulsion technology $t$ to be assigned to bus route $l$. The $0-1$ binary decision variable TUS is equal to 1 if and only if technology $t$ is associated with bus route $l$.

The parameter $a$ is the annualization factor, calculated according to Eq. 2:

$$
a=\frac{(i+1)^{n} i}{\left((i+1)^{n}-1\right)}
$$

with $i=$ interest rate and $n$ the time horizon of the investment.

The most important model constraints are energy balance equations at stops.

Energy balances at stops essentially impose that: 
- the energy in the battery or tank of the bus when coming to a bus stop $s$ equals the energy in the battery or tank at previous stop $s-1$ minus the energy consumed to travel from $s-1$ to $s$;

- the energy in the battery or tank when leaving bus stop $s$ equals the energy at arrival to the stop plus the energy added from any charging performed at the stop.

The equations are the same as described in the original model (Xylia et al. 2017), to which reference should be made as well for details about the handling of exceptions at start and end stops.

In the following section, we limit our description to the main differences from the original model, that is:

- the number of buses $N B$, which in the original model was a parameter defined for each route as the number of vehicles currently operating on the route, while in the present model version is an integer decision variable.

- the number of electric charging stations, which in the original model was directly given by the binary decision variable $U S(l, s, t)$, equalling 1 if vehicles with technology $t$ assigned to route $l$ are due to be recharged at stop $s$, while in our model is represented by the integer decision variable $N P$, calculated as detailed below.

\subsubsection{Number of buses}

The underlying assumption in the original model was that the service level on a route would be maintained if the number of buses currently operating on the route was maintained. However, Harris et al. (2020) observe that, depending on the technologies selected for storage and charging, a higher number of vehicles may be required to guarantee the same service. Trade-offs arise between longer charging times (allowing for example to better exploit a smaller number of recharging facilities), and the number of vehicles (which should be increased if too much time is spent in charging). To model this, a detailed approach using timetables could be used as in Wang et al. (2017) and in Rogge et al. (2018) to ensure that current schedule is maintained avoiding any delays or charging station congestion. However, the level of detail and computational effort required for an exact solution with such an approach is compatible with the operational level addressed in Wang et al. (2017) rather than with a long term network planning perspective. In fact, Rogge et al. (2018) resorted to genetic algorithms to solve a similar problem at a strategic level. Given the further complexity of considering several technologies as decision variables, which our case required, we used a simplified approach by calculating the number of buses according to Eq. (3):

$$
N B(l, t) \geq \frac{n_{\text {trip }}(l)\left[\operatorname{TUS}(l, t) \cdot t_{\text {trip }}(l)+\sum_{s} U S(l, s, t) \cdot t_{\text {ch } \arg e}(s, t)\right]}{t_{\text {op }}} \quad \forall s, l, t
$$

where $U S(l, s, t)$ is, as in the original model, a binary decision variable equalling 1 if vehicles with technology $t$ assigned to route $l$ are due to be recharged at stop $s ; t_{o p}$ is the available operational time per bus per year, in minutes; $t_{\text {trip }}(l)$ is the average 
travel time on route $l$, and $t_{\text {charge }}(s, t)$ is the charging time available at stop $s$ for technology $t$. Based on bus schedule, buses have longer idle times at end stations, which can be used for extended recharging: therefore, charging time additionally depends on stops. Inequality 3 basically ensures that, for each route, the number of buses meets the annual average net travel time demand. The approach is approximated, if compared e.g. with the more detailed probabilistic simulation model presented in Harris et al. (2020), where peak and off-peak period are treated differently. Nevertheless, it helps to reduce the risk of underestimating the number of vehicles to be purchased for the new fleet to meet average service requirements.

\subsubsection{Number of charging stations}

Conversely, there is, however, a risk of overestimation if applying the same approach as in the original model (Xylia et al. 2017) for calculating the number of charging stations for a regional intercity bus company in the Italian context. In fact, in the original model version, the total number of charging stations is apparently calculated as:

$$
N P_{O}(t) \geq \sum_{s} \sum_{l} U S(l, s, t) \quad \forall t
$$

That calculation indicates that charging stations, even those located at junction stops, cannot be shared by vehicles assigned to different routes, as each charging station would need to be dedicated to the corresponding route $l$. What may be reasonable in an urban context with a high number of trips and a high risk of congestion, could lead to excessive investment in charging stations with low utilization rates in an intercity context, where trips on a route can be infrequent. A detailed approach would require solving charging location and scheduling problems at the same time, using the actual timetable, as exemplified by Wang et al. (2017) for the city of Davis, and by Rogge et al. (2018) for the city of Aachen. However, we considered that the computational and data collection effort required to implement such an approach at an intercity level is more in line with the needs of operational planning of electric recharging, rather than with the strategic planning of several alternative technologies on the same network. For this reason, an intermediate approach was implemented. For CNG vehicles, which generally have higher ranges and relatively quicker charging times than electric vehicles, it was assumed that the risk of simultaneous refilling needs for vehicles from different routes at the same charging stations was negligible, and that the infrastructure, which is moreover generally more expensive than power charging, could better be shared among vehicles assigned to different routes. For CNG, the number of stations $N P$ is thus determined according to Eq. 5 as:

$$
N P(s, c n g)=\sum_{l} U S(l, s, c n g) \quad \forall s
$$

Given the above considerations regarding BEV charging, we concluded that sharing a single charging station between all routes would carry a high risk of congestion and delays only where, based on the timetable, there generally was a high 
probability of simultaneous arrivals at the charging stop. In that case, the optimization procedure needed to be constrained so that two or more charging stations would be installed at critical charging stops. For this purpose, a simultaneity coefficient $c(s)$ was preliminarily calculated for each stop based on the timetable: the coefficient $c(s)$ was set to 1 if at least three vehicles from different routes were to coincide at the given stop at least once in any $24-\mathrm{h}$ period, and to 0 otherwise. Within the optimization model, $N P$ was then calculated for each stop with the aid of auxiliary binary variables denoted as follows as $\delta_{i}$ and $\gamma_{j}$, and of constants $M$ (fixed arbitrary large number) and $\varepsilon$ (fixed arbitrary small number, see e.g. Williams 2003) according to Eqs. 6-16, applying at every stop $s$ :

$$
\begin{aligned}
& N P(s, e l)=\delta_{1}(s, e l)+\delta_{2}(s, e l)+\delta_{3}(s, e l) \\
& \sum_{l} U S(l, s, e l)+\gamma_{1}(s, e l) \geq 1 \\
& \sum_{l} U S(l, s, e l)-(M+\varepsilon) \cdot\left(1-\gamma_{1}(s, e l)\right) \leq 1-\varepsilon \\
& \sum_{l} U S(l, s, e l)+\gamma_{2}(s, e l) \geq 2 \\
& \sum_{l} U S(l, s, e l)-(M+\varepsilon) \cdot\left(1-\gamma_{2}(s, e l)\right) \leq 2-\varepsilon \\
& \sum_{l} U S(l, s, e l)+\gamma_{k}(s, e l) \geq k \\
& \sum_{l} U S(l, s, e l)-(M+\varepsilon) \cdot\left(1-\gamma_{k}(s, e l)\right) \leq k-\varepsilon \\
& \gamma_{1}(s, e l)+\gamma_{2}(s, e l)+\gamma_{k}(s, e l)-3 \cdot\left(1-\delta_{1}(s, l) \geq 0\right. \\
& \gamma_{1}(s, e l)+\gamma_{2}(s, e l)+\gamma_{k}(s, e l)-(M+\varepsilon) \cdot\left(1-\delta_{1}(s, e l)\right) \leq 3-\varepsilon \\
& \left.\gamma_{1}(s, e l)+\gamma_{2}(s, e l)-c(s)+M \cdot \delta_{2}(s, e l)\right) \leq M \\
& \gamma_{1}(s, e l)+\gamma_{2}(s, e l)-c(s)+(1+\varepsilon) \cdot\left(\delta_{2}(s, e l)\right) \geq \varepsilon \\
& \left.\gamma_{1}(s, e l)+\gamma_{k}(s, e l)-c(s)+M \cdot \delta_{3}(s, e l)\right) \leq M-1 \\
& \gamma_{1}(s, e l)+\gamma_{k}(s, e l)-c(s)+(1+\varepsilon) \cdot\left(\delta_{3}(s, e l)\right) \geq \varepsilon-1
\end{aligned}
$$


The binary variables $\gamma_{1}, \gamma_{2}$ and $\gamma_{k}$ are used as flags, and according to Eqs. 7-12 they indicate whether the total number of routes requiring recharging at the same stop is equal to:

- zero (all flags at 1$)$;

- $1\left(\left(\gamma_{1}=0\right.\right.$, all other flags at 1$)$;

- $\quad$ an integer value between 2 and $k-1\left(\gamma_{1}\right.$ and $\gamma_{2}$ at 0 and $\left.\gamma_{k}=1\right)$;

- an integer value larger or equal to $k$ (all flags at 0 ).

According to Eqs. 6 and 13-18, the number of charging stations at each stop is set at:

- zero, if no charging is performed on any route;

- 1 , if charging is performed for one route, or for at least two routes but with zero risk of simultaneity;

- 2 if charging is performed for 2 to $k-1$ routes with some risk of simultaneity;

- 3 if charging is performed for $k$ or more routes with some risk of simultaneity. The procedure can be further generalized for systems with more or less routes intersecting at junction stops. Based on the preliminary analysis of routes, $k$ was set at 5 for our case study.

\subsection{Emission assessment framework}

Direct carbon equivalent and air pollutant emissions arise only from fuel combustion in internal combustion engines, and are calculated as exemplified in Eq. 19 for tank to wheel $\mathrm{CO}_{2}$ equivalent emissions.

$$
C \mathrm{O}_{2} e q_{T T W}(t)=\sum_{l} n_{\text {trip }}(l) \cdot L_{\text {trip }}(l) \cdot c o_{2} e q_{T T W}(t) \cdot T U S(t, l) \cdot d y
$$

Emission factors for $\mathrm{NO}_{\mathrm{x}}, \mathrm{PM} 10$, and carbon equivalent emissions for the technologies of concern are obtained from literature, in particular from the references reported in Table 1, and expressed in $\mathrm{g} / \mathrm{km}$. Carbon equivalent emissions are based on 100 years Global Warming Potentials (GWP). $\mathrm{NO}_{\mathrm{x}}$ are dangerous for human health in urban environments, but are additionally responsible for acid rain. The Euro VI standard imposes a drastic abatement of $\mathrm{NO}_{\mathrm{x}}$ emissions, which is achieved by manufacturers by introducing selective catalytic reduction (SCR), using urea as a reducing agent.

The impact of urea production should thus be included in the assessment of Euro VI vehicles, as shown in Fig. 1, which represents the system boundaries considered for emission assessment for WTT carbon equivalent emissions and for TTW emissions. Besides $\mathrm{NO}_{\mathrm{x}}$, also particulate matter PM10 is considered because of its impact on smog and human health (Donateo et al. 2015). For coherence with the context of application, Italian (Donateo et al. 2015; ISPRA 2014; Chinese et al. 2017) and European (Nylund and Koponen 2012; Nylund 2014) data sources were preferred wherever available, in particular for the electricity mix (Donateo et al. 2015; Chinese et al. 2017), and more generally for assessing WTT emissions. Such 


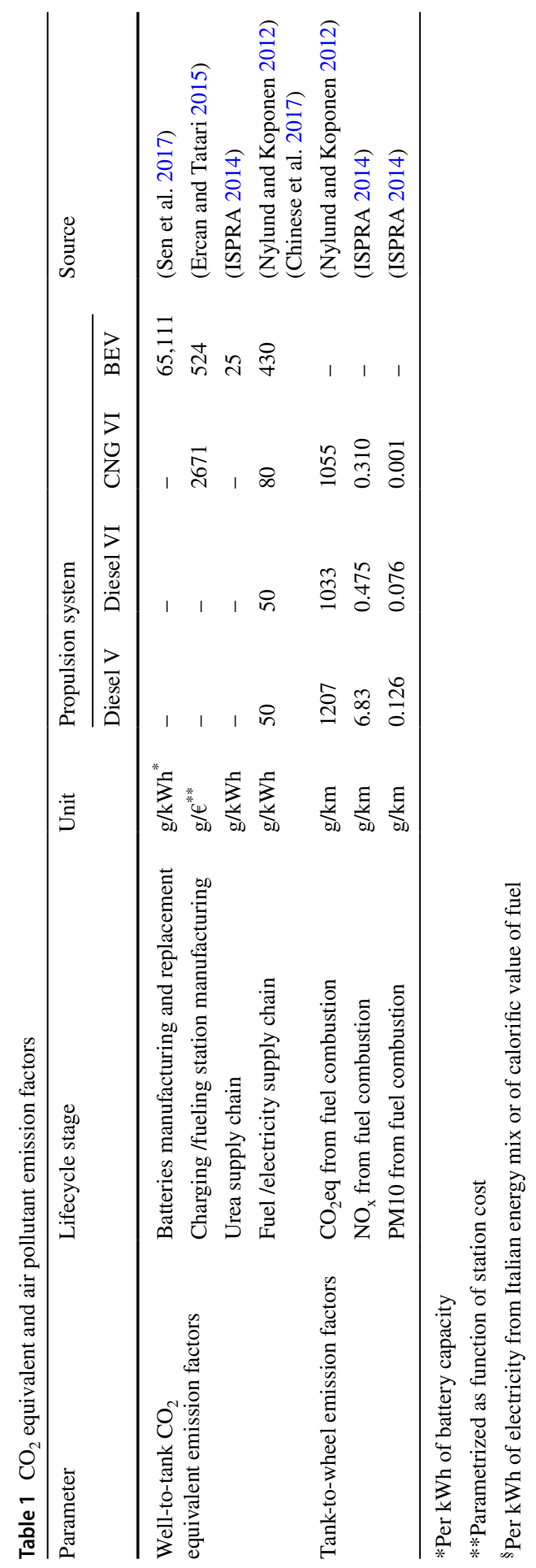




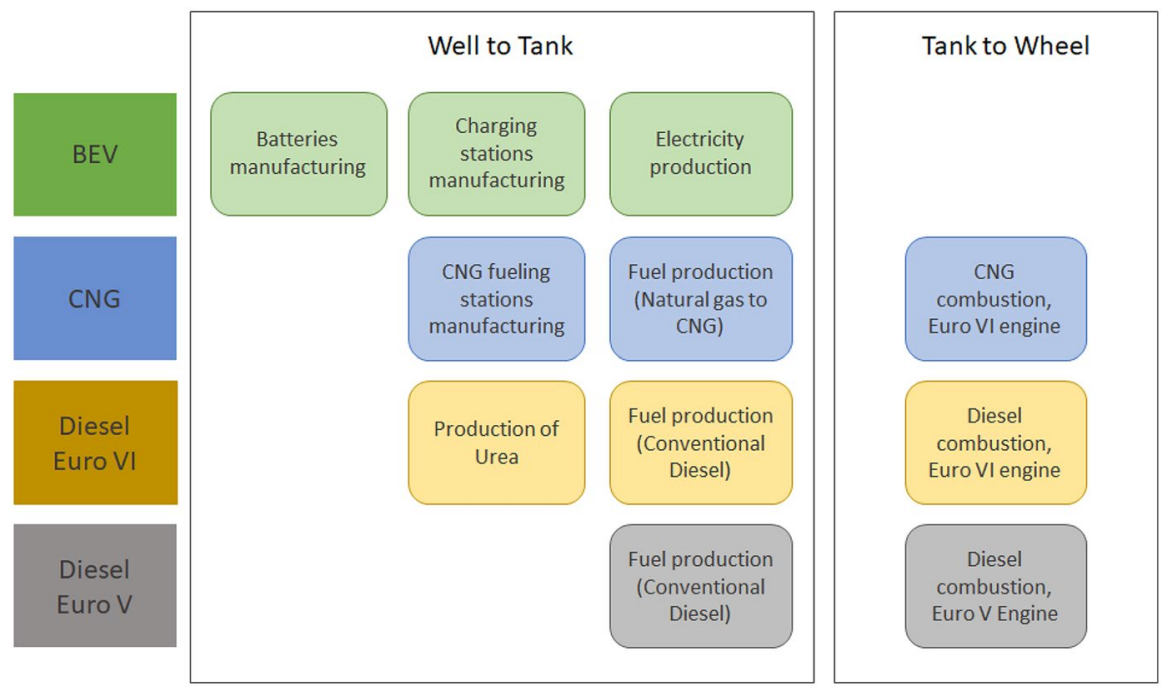

Fig. 1 Activities included in calculation of WTT $\left(\mathrm{CO}_{2} \mathrm{eq}\right)$ and TTW $\left(\mathrm{CO}_{2} \mathrm{eq}, \mathrm{NO}_{\mathrm{x}}, \mathrm{PM} 10\right)$ emissions

reference studies are mainly based on the traditional WTW emission calculation approach reported in Edwards et al. (2011) and on the methodology described in the 2009/28/EC Directive (RED methodology) for the assessment of emissions from biofuel quotas. We have integrated these data with American data sources which make use the GREET methodology (Wang 2001) and of a hybrid approach (Ercan and Tatari 2015), respectively, and used this information to derive parametric data about the impact of the manufacturing and replacement of batteries and charging stations. The choice we made was mainly based on to the paucity of data regarding the environmental impact of manufacturing charging stations, and on our desire to enable a comparison at least in terms of relative orders of magnitude.

On the other hand, emissions from vehicle construction were not included in the analysis, which is equivalent to the assumption that they are independent of the technology implemented. This is a limitation of our study, which could be overcome by future research gathering relevant experimental data and by elaborating specific life cycle inventories.

As a result, the assessment of WTT carbon equivalent emissions is achieved for battery electric buses according to Eq. 20:

$$
\begin{aligned}
\mathrm{CO}_{2} e q_{W T T}(e l)= & N B(e l) \cdot \frac{c o_{2} e q_{W T T b a t t}(e l)}{\text { durationbatt }(e l)} \\
& +\sum_{l} n_{\text {trip }}(l) \cdot t_{\text {trip }}(l) \cdot T U S(l, e l) \cdot \operatorname{cons}(e l) \cdot c o_{2} e q_{W T T f u e l}(e l) \cdot d y \\
& +\sum_{s} \frac{c o_{2} e q_{W T T s t a t}(e l)}{\text { durationstat }(e l)} \cdot N P(s, e l)
\end{aligned}
$$




\section{Case study and scenarios}

At the time of the research, the regional bus transport company investigated as a case study was operating in the South Eastern part of Friuli Venezia Giulia, an Italian region close to the border with Slovenia. The following sections describe the situation of the bus transport service, report the technical and economic data used for the analysis, and summarize the scenarios examined in this study.

\subsection{Case study description}

As shown in Fig. 2, which represents the route network in black and bus stops as red dots, the company was responsible for bus transport over an area of about 2400 $\mathrm{km}^{2}$. On average, extra urban buses operate for $19 \mathrm{~h}$ a day and 280 days a year, with a total average distance travelled of about 4.2 millions $\mathrm{km} / \mathrm{year}$.

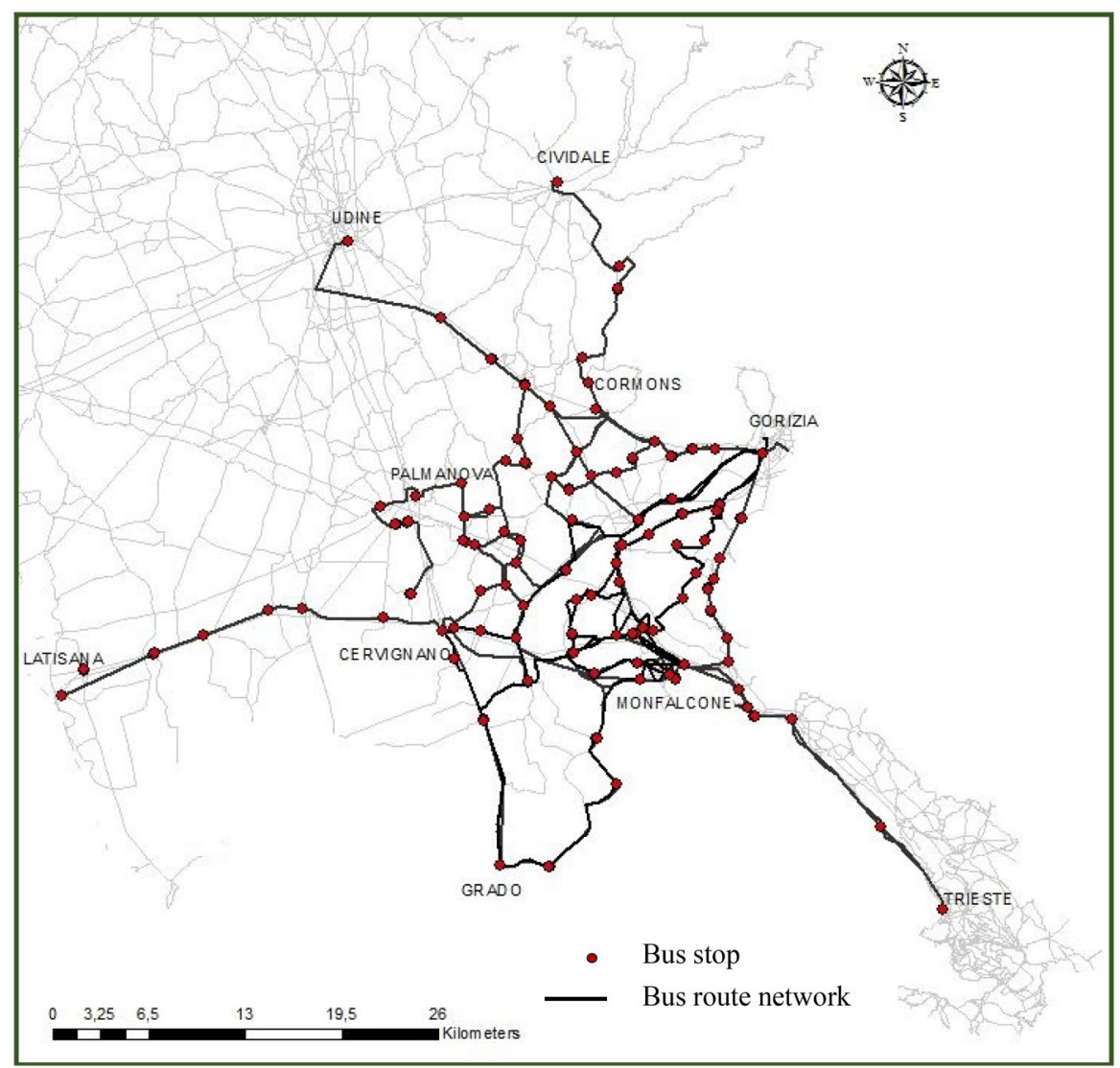

Fig. 2 Map of extra urban bus network and stops 
As shown in Table 2, routes are very diverse: they vary in length between some 20 and some $80 \mathrm{~km}$, and the number of services may be very different between different routes, ranging between as little as 1 round trip per day to more than 50 round trips per day. Idling stops at end stations last on average $25 \mathrm{~min}$, whereas two minutes is the idling time generally scheduled for each intermediate bus stop.

The current fleet is made up of diesel vehicles of various Euro emission classes. It was agreed with the technical staff of the company that the current fleet could be roughly considered as a Euro V fleet, as far as fuel economy and emissions are concerned.

\subsection{Technical and economic data}

The technical and economic data used for the analysis are summarized in Table 3. An agreement was reached with the company administration that a reasonable time horizon for the analysis is $n=15$ years, and $i=8 \%$ is an acceptable interest rate. Batteries are assumed to last 5 years (Rothgang et al. 2015; Zhang et al. 2020), thus manufacturing and two replacements are included in the analysis for $\mathrm{BEV}$ based options. It must be noted that the capital outlay for BEVs is about $50 \%$ higher than that for CNG buses (excluding the cost of batteries), while inversely, the cost of CNG fuelling stations is about $50 \%$ higher than for electric fast charging stations. Based on previous studies (Büyüközkan et al. 2018) the cost of CNG filling stations is assumed to be substantially lower when high pressure natural gas transport pipelines exist within proximity of possible locations, as this makes it possible to avoid the additional compression of natural gas required to obtain $\mathrm{CNG}$ from low pressure natural gas distribution networks. Low pressure natural gas distribution is available in all the urban centres in the area under consideration.

Table 2 Energy, environmental, and capacity indicators for the existing bus system

\begin{tabular}{|c|c|c|c|}
\hline Total fuel consumption [MWh/year] & & & 19,262 \\
\hline Total WTW $\mathrm{CO}_{2}$ eq emissions [t/year] & & & 6012 \\
\hline Total $\mathrm{NO}_{\mathrm{x}}$ emissions [t/year] & & & 28.6 \\
\hline Total PM10 emissions [t/year] & & & 0.5 \\
\hline Number of buses & & & 51 \\
\hline \multirow[t]{2}{*}{ Number of routes (round trips) } & & & 18 \\
\hline & Median & Min & $\operatorname{Max}$ \\
\hline Round trips per route per day & 6 & 1 & 56 \\
\hline Route length (one way) $[\mathrm{km}]$ & 36 & 18 & 77 \\
\hline Trip duration (one way)[min] & 59 & 25 & 110 \\
\hline
\end{tabular}




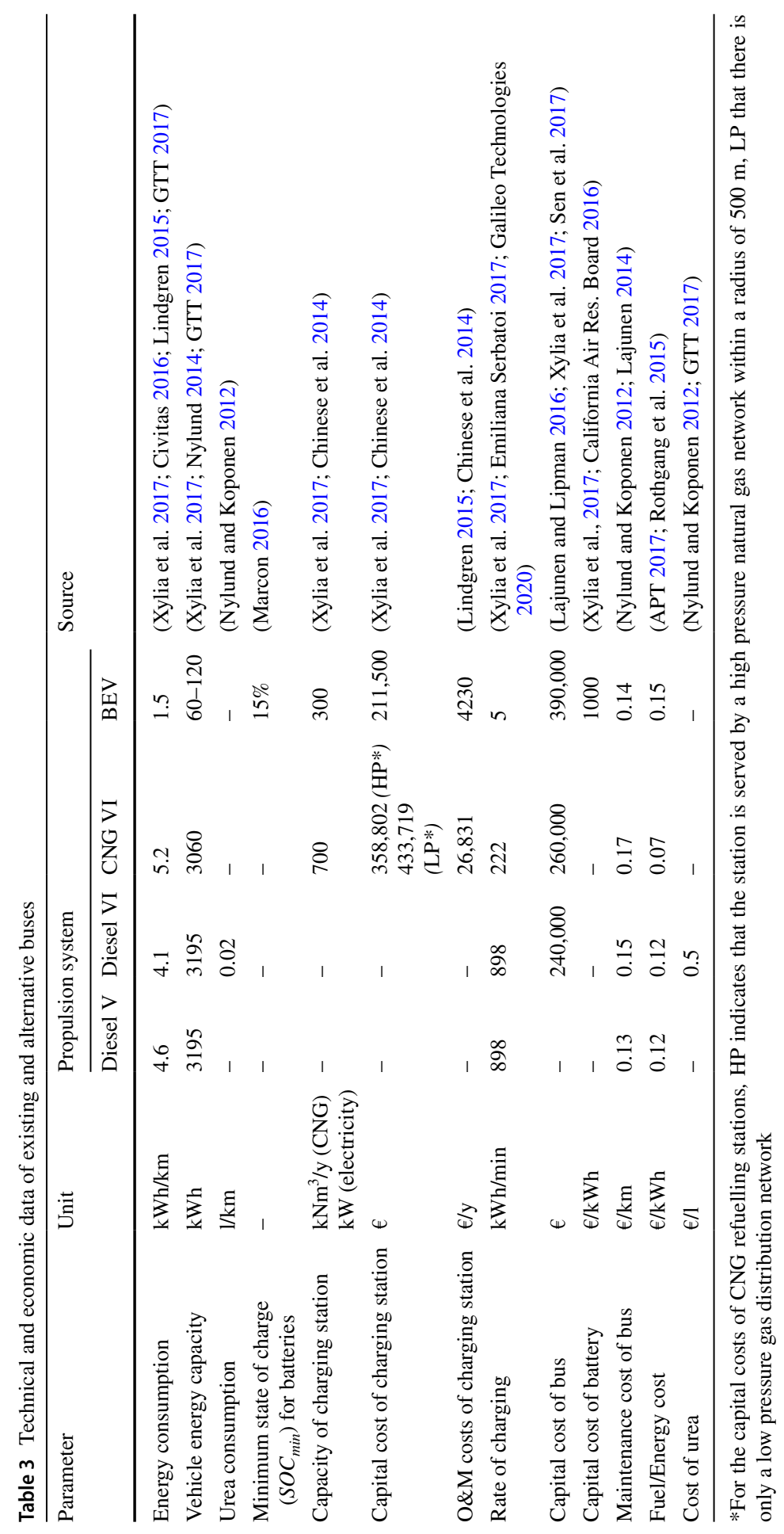




\subsection{Definition of emission constrained scenarios}

In order to compare alternative options to improve the environmental performance of the bus network, following scenarios have been defined:

Business as Usual (BAU): in this scenario, the current situation is reproduced by running the model for the Diesel V technology only, in order to estimate the number of buses, energy consumption, emissions and costs. For the sake of comparison, it is assumed that the fleet will operate for fifteen years at the maintenance costs indicated, and that engine performance will not vary over time. It is assumed that existing fuelling stations are to be used for the whole period, and the initial capital costs of diesel fuelling stations, as well as those of the fleet, are to be treated as sunken costs and set to zero. The scenario is developed exclusively for reference and comparison: maintaining current Diesel Euro V buses or purchasing used vehicles are not considered as a feasible option for any of the emission reduction scenarios defined as follows.

$50 \% \mathrm{CO}_{2}$ emissions: in this scenario, total yearly WTW carbon equivalent emissions are constrained to be lower or equal to half of the WTW carbon equivalent emissions calculated in the BAU scenario. Here and in all environmental improvement scenarios, the technologies considered for optimization include Diesel Euro VI buses, CNG Euro VI buses and battery electric buses with either a $60 \mathrm{kWh}$ battery or a $120 \mathrm{kWh}$ battery.

Minimize $\mathrm{CO}_{2}$ emissions: in this scenario, WTW carbon equivalent emissions are minimized.

$50 \% \mathrm{NO}_{x}$ emissions: in this scenario, total yearly $\mathrm{TTW} \mathrm{NO}_{\mathrm{x}}$ emissions are constrained to be lower or equal to half of the TTW $\mathrm{NO}_{\mathrm{x}}$ emissions calculated in the BAU scenario.

50\% PM10 emissions: in this scenario, total yearly TTW PM10 emissions are constrained to be lower or equal to half of the TTW PM10 emissions calculated in the BAU scenario.

\section{Results and discussion}

The model was implemented according to the flowchart reported in Fig. 3, which also indicates the software tools used for the implementation. Spatial information-including the bus transport network topology represented in Fig. 2, and the topology of the regional natural gas transport networks (Chinese et al. 2014) — has been pre-processed in ArcGIS Desktop 10.5.1 (ESRI 2017). We have thus been able to calculate spatially-explicit input data, including the distances between stops as well as the cost functions for CNG fuelling stations (which depend on the Euclidean distance between each potential refuelling stop and the closest HP natural gas transport network). In the data processing phase, we have also integrated the bus timetables, made available by the bus company as Excel spreadsheets, with the spatial information. In this way, we have been able to evaluate the input data that depends on both the bus schedule and the location of stops. That is the case of the binary indicator for the risk of simultaneous recharging at the 


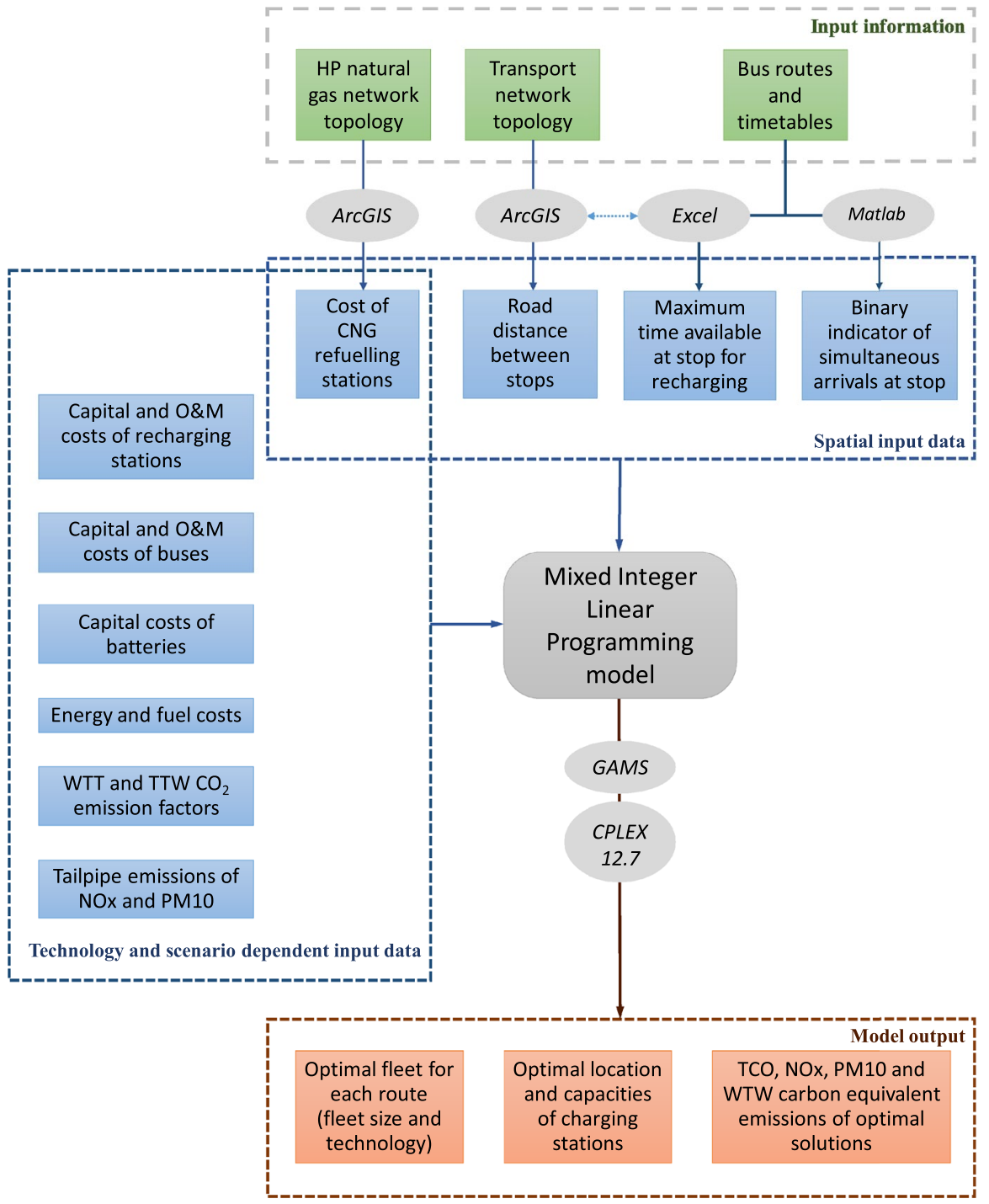

Fig. 3 Flowchart of model calculation processes and software tools used

same stop $c(s)$, which was calculated as described in Sect. 2.2.2. by developing a Matlab script, as well as of the maximum time available at each stop for recharging $t_{\text {charge }}(s, t)$, which is estimated as the minimum idling time scheduled at the given stop $s$ in any reference-day. The Mixed Integer Linear Programming model was implemented in GAMS, and solved with CPLEX 12.7 (McCarl et al. 2008) for each of the emission constrained scenarios defined in Sect. 3.3. Additionally, technology dependent input data subject to uncertainty have been changed to perform a worst/best case scenario analysis as specified in Sect. 3.4. Computational 
times on a i7 PC were reasonable, reaching about two hours for the most complex scenarios.

\subsection{Optimal system configurations under different emission reduction scenarios}

Table 4 shows the fleet composition and the mix of technologies used along the routes in the developed optimization scenarios. It can be deduced that, under the constraint of reducing $\mathrm{NO}_{\mathrm{x}}$ emissions alone, the use of Euro VI vehicles instead of the current fleet is, in the main, sufficient for achieving $N O_{x}$ emission reduction targets. The $50 \% \mathrm{NO}_{x}$ scenario in this way corresponds to a full Euro VI scenario without any other technologies.

In order to achieve 50\% PM10 emission reduction targets, however, the use of new Euro VI buses alone is not sufficient. For that purpose, the introduction of CNG buses is preferred, which, even accounting for new refuelling stations, are less expensive than the outlay required for battery electric technologies on the network under consideration.

Figure 4 shows the allocation of fuels and infrastructure to the routes of the network in the 50\%PM10 scenarios. The routes of the CNG bus network are marked in blue, whereas Euro VI Diesel buses are used on the routes marked in black. Three CNG fuelling stations (red dots in Fig. 4) are introduced at three end stops. The six routes to which $\mathrm{CNG}$ is allocated are relatively short routes with a high number of junctions, and an average or above average trip frequency. Having set an emission constraint with a cost minimization objective, the optimal configuration allocates CNG to a restricted number of routes where the need for refuelling stations is minimum and the fuel consumption is particularly high.

Table 4 Optimized allocation of vehicles and technologies to routes in BAU and emission reduction scenarios

\begin{tabular}{|c|c|c|c|c|c|c|}
\hline & \multirow[t]{2}{*}{ Propulsion system } & \multicolumn{5}{|c|}{ Scenarios } \\
\hline & & BAU & $-50 \% \mathrm{CO}_{2} \mathrm{eq}$ & Min $\mathrm{CO}_{2} \mathrm{eq}$ & $-50 \% \mathrm{NO}_{\mathrm{x}}$ & $-50 \%$ PM10 \\
\hline \multirow[t]{5}{*}{ Number of buses } & Diesel V & 51 & - & - & - & - \\
\hline & Diesel VI & - & 31 & - & 51 & 30 \\
\hline & CNG VI & - & - & - & - & 21 \\
\hline & BEV $60 \mathrm{kWh}$ & - & 10 & - & - & - \\
\hline & BEV $120 \mathrm{kWh}$ & - & 10 & 51 & - & - \\
\hline \multirow[t]{5}{*}{ Number of routes } & Diesel V & 18 & - & - & - & - \\
\hline & Diesel VI & - & 5 & - & 18 & 12 \\
\hline & CNG VI & - & - & - & - & 6 \\
\hline & BEV $60 \mathrm{kWh}$ & - & 11 & - & - & - \\
\hline & BEV $120 \mathrm{kWh}$ & - & 2 & 18 & - & - \\
\hline \multirow{3}{*}{$\begin{array}{l}\text { Number of charg- } \\
\text { ing stations }\end{array}$} & CNG VI & - & - & - & - & 3 \\
\hline & BEV $60 \mathrm{kWh}$ & - & 17 & - & - & - \\
\hline & BEV $120 \mathrm{kWh}$ & - & 7 & 28 & - & - \\
\hline
\end{tabular}




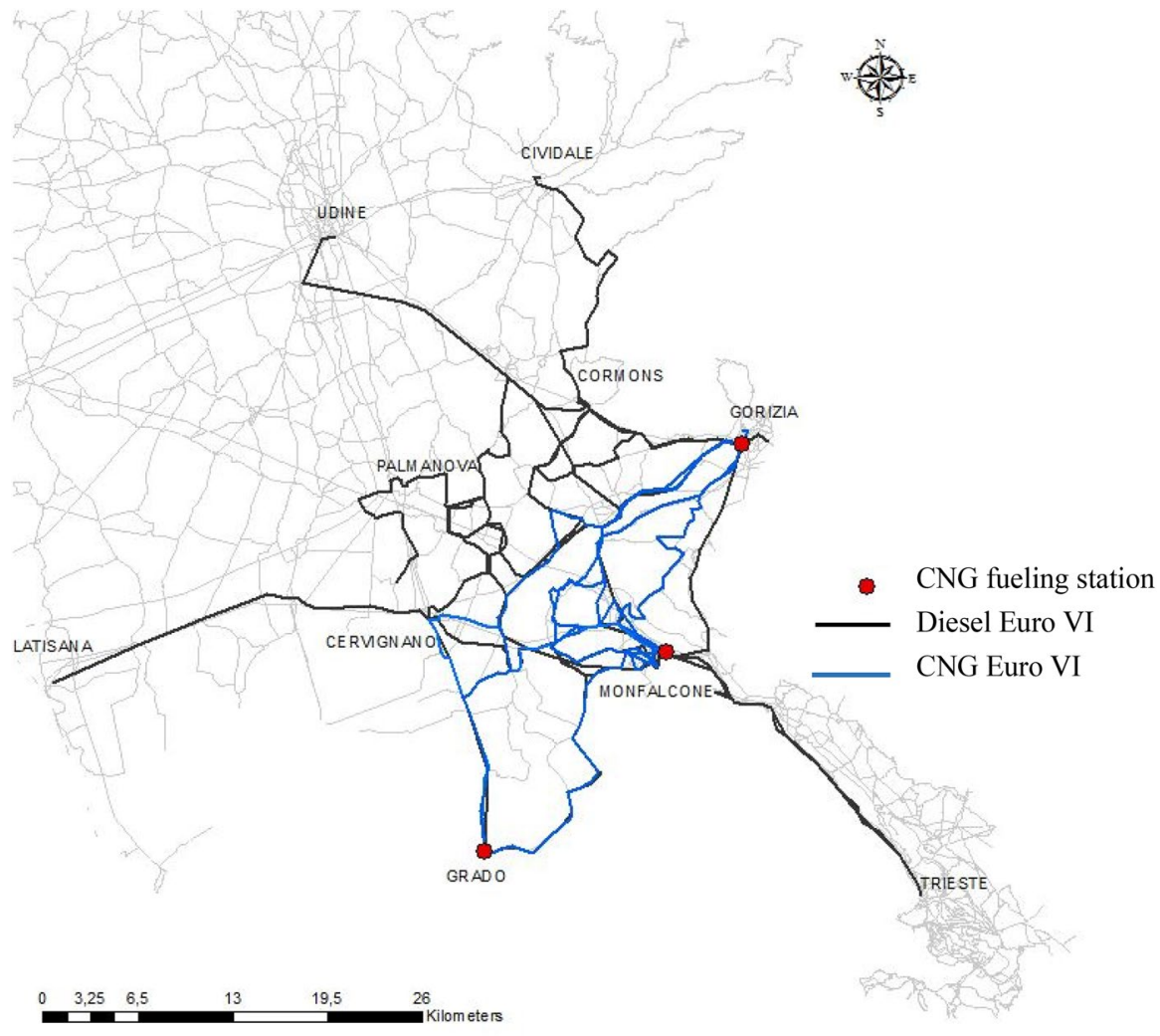

Fig. 4 Map of optimal system configuration for-50\% PM10 scenario

Table 1 shows that the TTW carbon emission performance of CNG Euro VI buses in terms of carbon equivalent emissions may be worse than that of corresponding Diesel Engines, mainly due to the GWP associated with uncontrolled leaks of $\mathrm{CH}_{4}$.

For this reason, a combination of BEV and Euro VI Diesel is preferred when targeting 50\% carbon equivalent emission reduction.

Since the current mix of electricity generation in Italy includes mainly fossil fuel sources (Donateo et al. 2015), more routes need to be electrified to achieve a 50\% carbon emission reduction target. In Table 4 and Fig. 5 it can be seen that 13 routes are electrified to halve carbon equivalent emissions at minimum costs (whereas serving only six routes with $\mathrm{CNG}$ was enough to achieve a 50\% PM10 emission reduction). The optimization tends to favour routes with a relatively lower trip frequency than in the 50\% PM10 scenario, in order to keep the number of costly vehicles to a minimum. Longer routes are generally preferred for electrification in the $-50 \% \mathrm{CO}_{2}$ scenario, even though this would require as many as 24 recharging stations. Due to the high cost of storage, $60 \mathrm{kWh}$ systems are generally preferred, apart from the two longest routes (in red in Fig. 5), to which ten $120 \mathrm{kWh}$ battery electric (BE) buses and seven charging stations are assigned. 


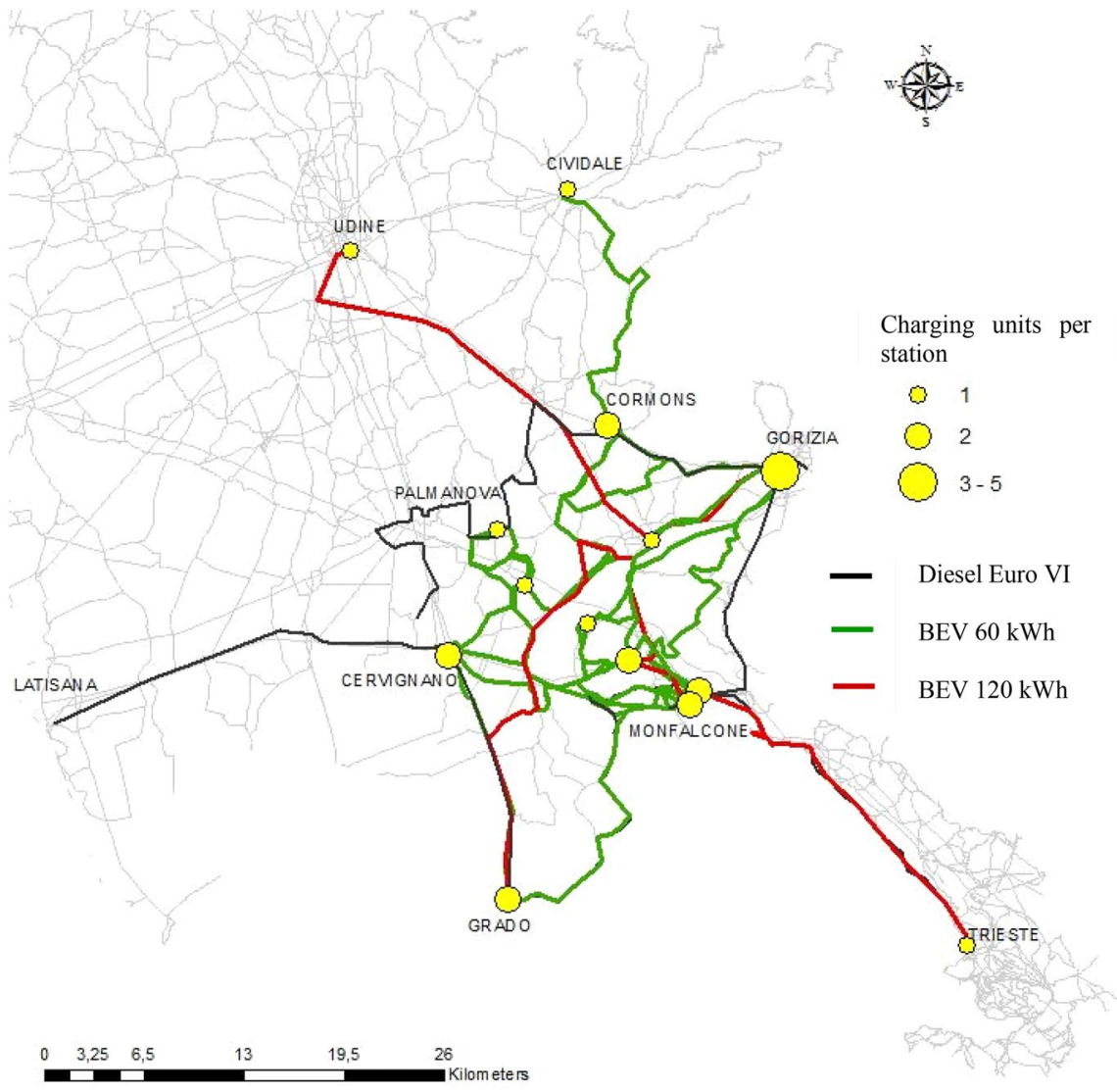

Fig. 5 Map of optimal system configuration for- $50 \% \mathrm{CO}_{2} e q$ scenario

$60 \mathrm{kWh}$ electric storage is generally preferred due to the high cost of batteries, but in the "Minimize $\mathrm{CO}_{2}$ eq emissions" scenario, in which all routes are electrified, $120 \mathrm{kWh}$ batteries are selected exclusively. In fact, energy consumption being equal, the use of larger storage systems lowers the emissions of GHG on a WTW basis by limiting the requirement for and number of charging systems, whose contribution to WTW emissions is significant.

\subsection{Economic performance}

That batteries are a main cost component is confirmed by the economic results displayed in Fig. 6, where annual equivalent systems cost for each scenario are compared. The investment required for batteries is greater than that required for charging stations, in particular, more than double that when $120 \mathrm{kWh}$ batteries are selected exclusively. Together with the high cost of battery electric vehicles, which represent the main cost component in the $-50 \% \mathrm{CO}_{2}$ emissions scenario, this makes electric 
7

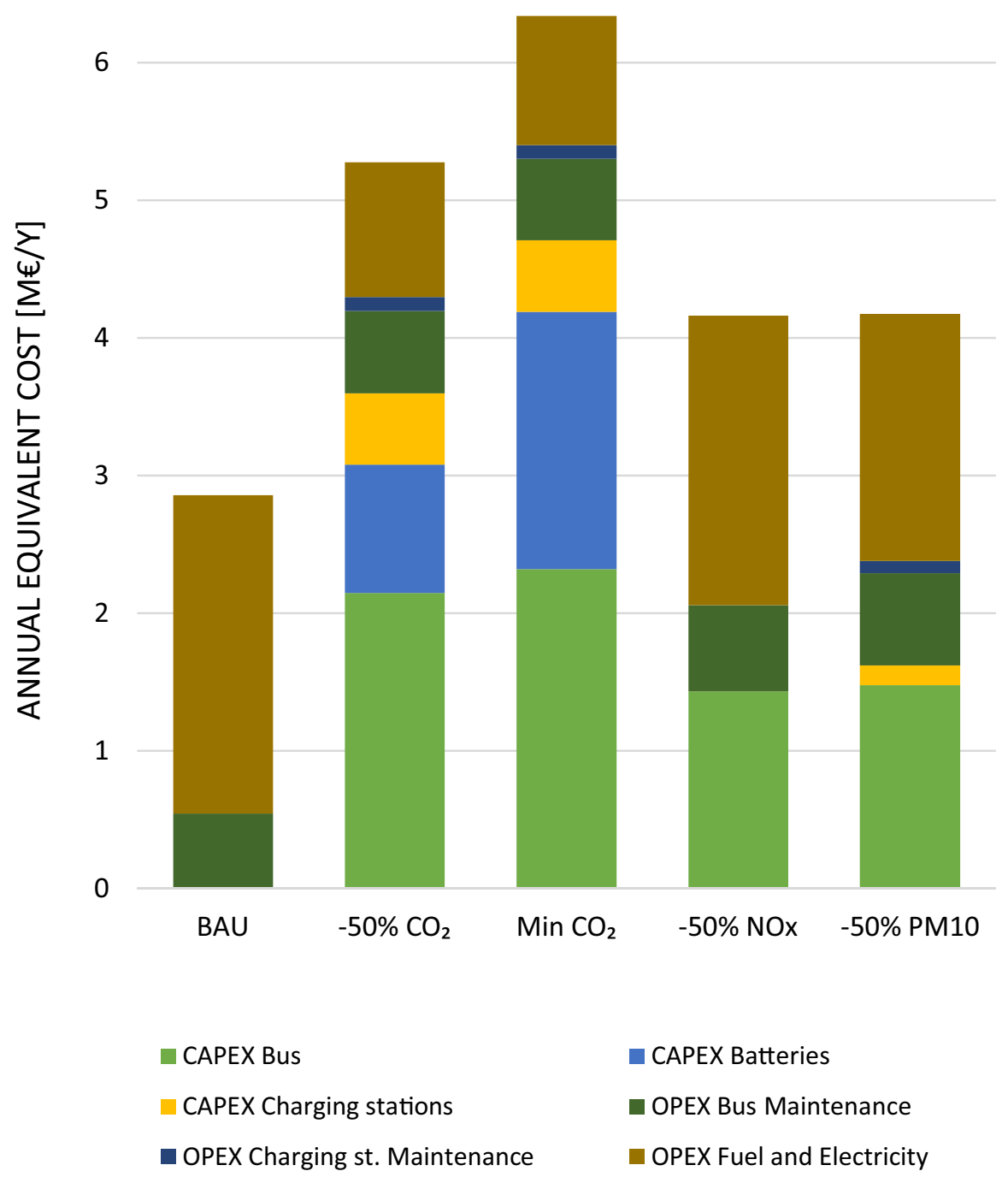

Fig. 6 Annual equivalent system cost for BAU and emission reduction scenarios

vehicle based systems between 25 and $50 \%$ more expensive than an entirely new Euro VI bus fleet, depending on the scenario. While the price of electricity (see Table 3) may be deemed relatively high, and corresponding cost share figures are significant, Fig. 6 shows that even if electricity costs were zero, electrified systems (Min $\mathrm{CO}_{2}$ and-50\% $\mathrm{CO}_{2}$ emissions scenarios) would be barely competitive with Euro VI or CNG based scenarios. 




Fig. 7 Annual $\mathrm{CO}_{2}$ equivalent for $\mathrm{BAU}$ and emission reduction scenarios

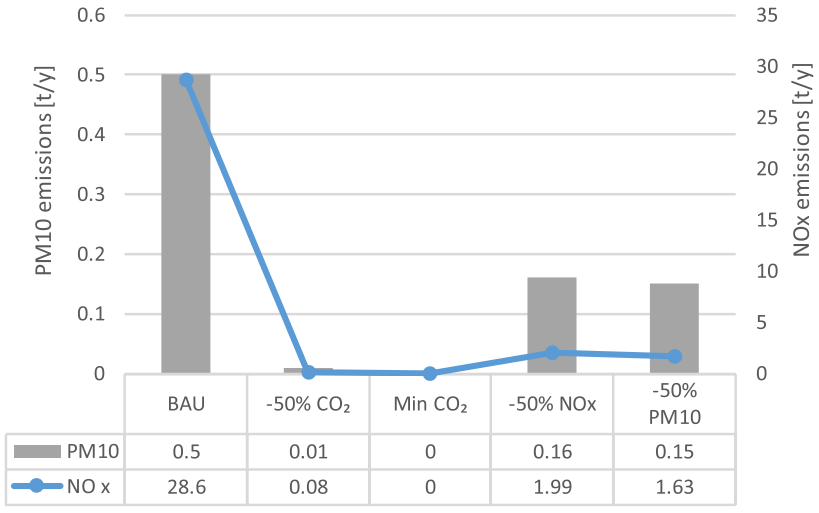

Fig. 8 Annual $\mathrm{NO}_{\mathrm{x}}$ and PM10 emissions for BAU and emission reduction scenarios

\subsection{Environmental performance}

In terms of $\mathrm{CO}_{2}$ emissions, even fleet renewal with Euro VI vehicles alone brings about some reduction from BAU, as can be seen in Fig. 7.

Figure 8 shows that the emissions of other pollutants in the $50 \% \mathrm{NO}_{x}$ (Diesel only) and in the 50\% PM10 (with CNG) are actually very similar, while they are assumed to be null for electric vehicles, as highlighted in Minimize $\mathrm{CO}_{2}$ and $50 \%$ $\mathrm{CO}_{2}$ emissions scenarios. On the other hand, Fig. 7 also shows that the use of CNG in the 50\% PM10 scenario causes an increase in the emissions of GHG even compared with the $B A U$ scenario.

The gap is larger when WTW pathway is considered because of WTT related GHG emissions, which mainly occur along the natural gas supply chain and partly for the construction of fuelling stations. While the impact of fuelling or recharging stations may well be uncertain due to lack of data, as discussed above, the results 
nevertheless confirm that it should at least be investigated for new systems implying the construction of additional infrastructure.

In Fig. 9, a parametric analysis shows the correlation between the environmental benefits of GHG emission reductions in the system studied and the system costs.

The carbon equivalent emission reduction constraint is gradually changed between $11 \%$, which is the maximum reduction achieved by sheer Diesel fleet renewal (represented as a grey square in Fig. 9), and 51\%, which is the maximum reduction, achieved with full network electrification in the minimize $\mathrm{CO}_{2}$ emissions scenario (red triangle in Fig. 9). All the intermediate scenarios thus obtained (green dots in Fig. 9) envisage a mix of Euro VI Diesel and battery electric buses.

Additional annual equivalent costs compared with the $B A U$ scenario are divided by total emission reduction from the $B A U$ scenario, thereby enabling us to calculate the average costs of $\mathrm{CO}_{2}$ eq reduction through optimization of the inter urban regional network of our study. Such costs range between 670 and $1920 € /$ tonCO $_{2}$ eq, which is elevated compared with e.g. the implicit carbon price of some renewable energy sources (Marcantuoni and Ellerman 2015) or even with carbon capture costs (see e.g. Mandova et al. 2019 for an industrial application).

Nevertheless, the overall analysis of the scenarios has confirmed that electrification is technically feasible even at the inter-urban, regional scale examined in the present study.

Figure 9 highlights that the average cost of $\mathrm{CO}_{2}$ abatement for the bus transport system would be maximized by a fleet renewal with Euro VI buses, due to the small reduction in carbon emissions which would be achieved. The minimum average cost is achieved by electrifying the four routes which produce the highest emissions while using Euro VI buses on the remaining routes. A carbon emission reduction of about $44 \%$ from the BAU scenario is thus achieved. By electrifying additional routes, carbon equivalent emissions are further reduced, but average $\mathrm{CO}_{2}$ abatement costs rapidly increase. Overall, aiming at full electrification brings about very limited benefits (see also Fig. 7) at significant additional expense. For a rational planning of fleet and infrastructure deployment, spatially explicit optimization models with an environmental perspective can thus be very useful in directing investment of resources to routes which provide greatest benefits in terms of outlay vs reduction in emissions.

\subsection{Sensitivity analysis via worst/best case scenario analysis}

The uncertainty inherent in the various estimates of optimization model parameters might be addressed by a sensitivity analysis.

For this purpose, we chose to perform a worse-best case scenario analysis, cited by EC (2017) in the "Better regulation toolbox" as the first potential approach to testing the sensitivity of the final outcome to changes in parameters. Worse/best case scenario analysis is performed by adopting all of the most conservative and all of the least conservative values for the parameters used in the calculation of performance indicators. 


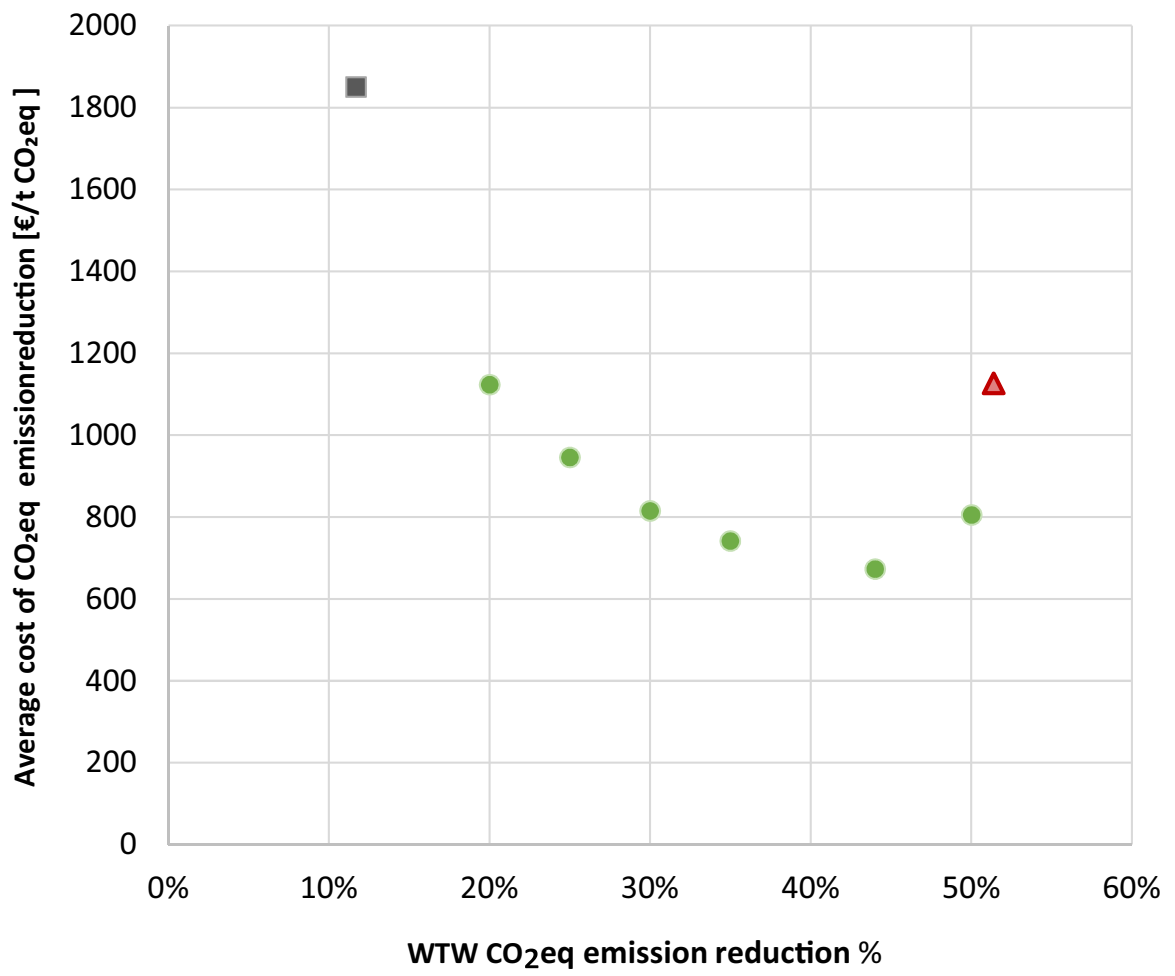

Fig. 9 System average cost of $\mathrm{CO}_{2}$ equivalent emission abatement depending on achieved reduction percentage

In this study, we performed a worst/best case scenario analysis to determine how the objective function (annual equivalent system costs) and the optimized system configuration (the number of routes served by buses with alternative powertrains) were affected by extreme changes in uncertain parameters. Scenarios were run, using values identified in literature (see Table 5), in which parameters ranged between extremes -more specifically, the most conservative (worst) and the least conservative (best)—for assessing investments in alternative powertrains.

For instance, high costs of CNG and electricity with relatively low diesel oil prices are the most conservative conditions, and are therefore incorporated in the worst-case scenario. On the other hand, the technical and economic values reported in Table 3 are generally in the middle of the range, and are assumed to be the most likely values which correspond to our case study. To test the sensitivity of the model, we performed an unconstrained least-cost optimization, i.e. without the emission reduction constraints described in the scenario definitions above. The results show that Euro VI Diesel buses are the least cost option for re-fleeting in both the worst case and the reference case scenario. In the best case scenario, electric buses with $60 \mathrm{kWh}$ batteries would be preferred on almost all of the 18 routes, with only six routes served by 12 Euro VI Diesel vehicles. 
These six routes represent just about $4.3 \%$ of the total yearly travelled distance on the bus network. Figure 10 reports the breakdown of the annual equivalent systems costs for the best, worst, and reference case. To give a better insight into what would make alternative powertrains, particularly electric vehicles, competitive with traditional technologies, an additional optimization run is performed by forcing the system to adopt electric buses with $60 \mathrm{kWh}$ batteries on all routes, under worst, reference, and best case conditions. The cost breakdown of this additional, all electric system configuration is also plotted in transparent colours in Fig. 10, from which it is possible to gauge how the costs of batteries and charging stations are subject to the greatest uncertainty, and in worst case conditions make the total system cost of electric buses more than twice as the corresponding Euro VI bus based system costs. Comparison of the optimized and the all-electric configurations under best-case conditions confirms the usefulness of optimization models in identifying uneconomical routes and disregarding these for electrification. Full electrification would increase annual costs by about $9 \%$ compared to the optimized configuration. This is mainly due to the additional costs of batteries and recharging stations, which cannot be offset by lower energy cost on such marginal routes due to lower usage, and therefore limited possibility of amortization.

\section{Conclusions}

There are several environmental and economic factors that need to be evaluated in the strategic planning of alternative propulsion systems for local public transport systems. In this paper, a bus network optimization model for the design of intercity bus transport networks in less intensely served rural areas has been presented. The model was developed to treat the number of vehicles as a decision variable, in order to simultaneously address bus fleet optimization issues. Compared to the multitude of planning models for electric charging stations which have emerged in recent years, the singularity of this approach is in the simultaneous evaluation of several alternative technologies, both electric and fossil-fuel based, conventional or otherwise, which makes the model particularly suitable for strategic network planning. In this study, the model was applied simultaneously to multiple possible scenarios, which led to the deployment of CNG fuelling stations, to the identification of optimal location for electric conductive charging stations, and to the identification of the least-cost fleet composition. Two battery size classes for electric buses were considered, as was the option of next-generation conventional diesel buses.

Being directed to the integrative assessment of several alternative technologies in a long-term perspective, the model also incorporates environmental impact indicators in the form of emission reduction constraints. In our study, a well-towheel carbon dioxide equivalent emission assessment based on Italian conditions has been included, as have tailpipe emissions of NOx and PM10, whose impact on local air pollution is of specific concern for local authorities. 





Based on case specific results, obtained here from the application of the model to a regional bus service which manages 18 routes between towns in North Eastern Italy, some policy conclusions can be drawn:

- Trade-offs between different environmental impact reduction objectives emerge frequently when considering different transport alternatives. In our study, this was the case with CNG, which, even accounting for the costs of dedicated refuelling stations, proved to be an economically attractive option when considering the reduction of air particulate, even though $\mathrm{CNG}$ vehicles don't perform as well as state of the art conventional diesel buses with regard to emissions of greenhouse gases. One should make decision makers aware of the fact that alternative powertrains or fuels are not equally favourable from every point of view. In this respect, a particularly desirable feature of the model is the simultaneous assessment of various emissions with an extended WTW approach, as well as of costs of outlay and management.

- The analysis of cost trends for carbon emission reduction has confirmed that the potentials of electric propulsion as a decarbonisation option for bus transport are striking, reaching up to as much as $50 \%$ in our case-study. When considering environmental benefits vs costs, such potentials are, however, limited by the high capital costs of electric systems. At present electricity prices in Italy make battery electric fleets much more expensive than corresponding conventional propulsion systems (e.g. between 27 and 52\% more expensive than Euro VI diesel bus systems, for the case study analysed). If the transition of regional transport to low-carbon systems is sought, policies centred on carbon pricing or carbon taxes would be insufficient or inapplicable, as carbon emission abatement costs related to bus transport are well beyond current and expected carbon prices. Significant specific incentives would then be needed, which could be justified in view of the additional advantages of some technologies in other environmental dimensions. The model proposed in this paper could also be used to guide and support local policy makers in devising targeted incentives such as capital grants or exemption from some energy taxes.

- Especially when support schemes apply, decision makers should give preference to the electrification of the routes most favourable from a cost/benefit point of view, which are more easily identified with the help of the model developed. Minimum support should be given to next generation diesel vehicles, which-when using adequate shares of sustainable biofuels-might nevertheless contribute to the decarbonisation of bus services on marginal routes.

- Joint fleet and network optimization is particularly needed for electric bus fleets, not only because of the costs and local impact of recharging infrastructure, but especially given the initial high outlays for vehicles and batteries: the latter have been found to account for up to $30 \%$ of annual equivalent system costs in extreme emission reduction scenarios, where even the longest intercity routes are converted to electric power by increasing the use of high capacity batteries. 


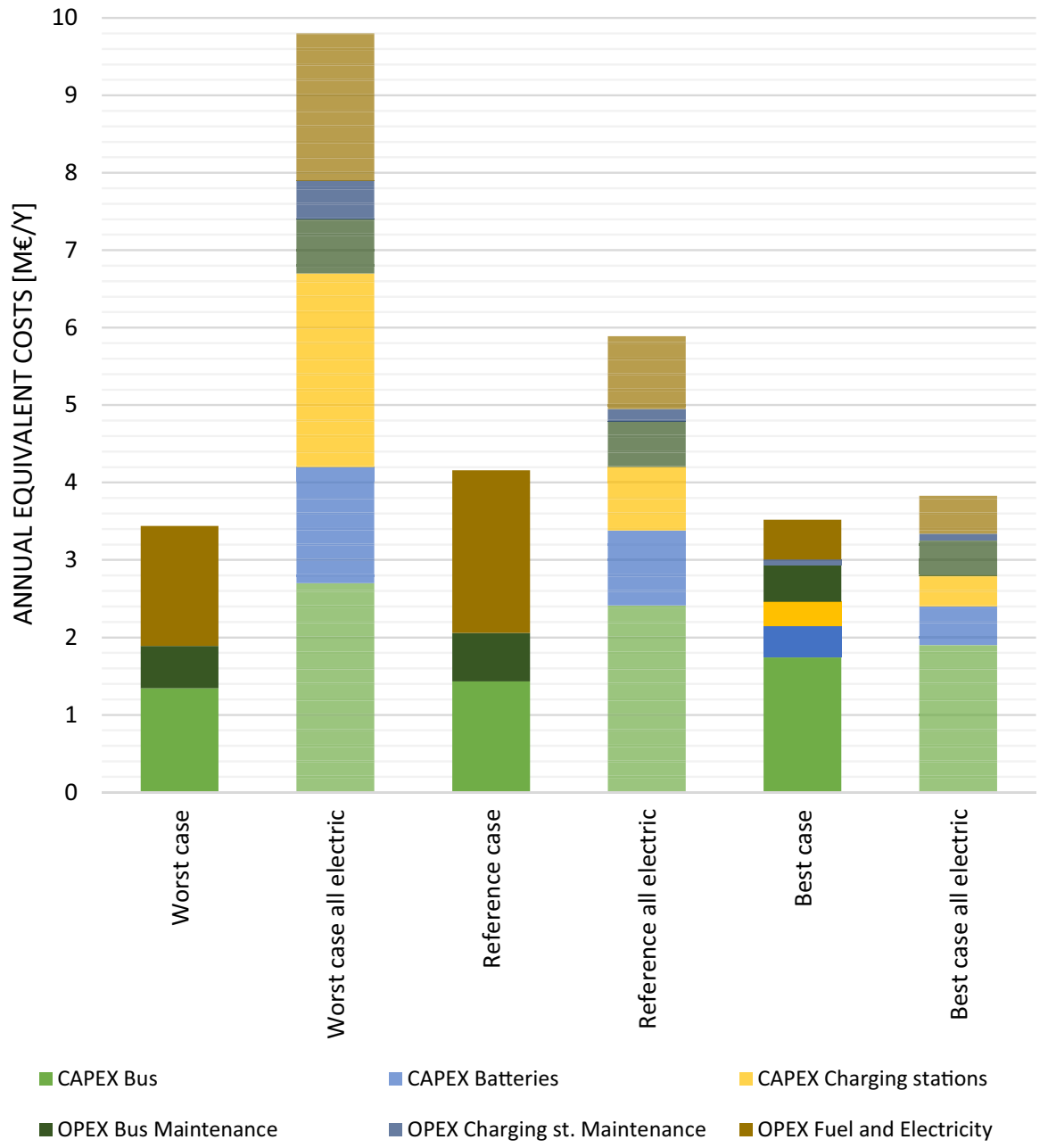

Fig. 10 Annual equivalent system costs for unconstrained, cost optimized configurations and for $60 \mathrm{kWh}$, all electric configurations under worst-, reference-, and best-case conditions

In this respect, it is plausible that the use of information from the literature and databases, although well documented, might have influenced the results obtained. To improve the accuracy of the model, future developments would benefit from integrating more detailed and realistic models of driving cycles and of energy storage systems aging, in particular, given the significant impact of batteries on the economic and environmental impact of electric bus fleets.

The model application has also confirmed that the environmental impact of manufacturing charging and/or refuelling stations may be limited, but is not inconsequential. It is recommended that the carbon footprint and the environmental impact of recharging stations of various technologies is investigated in specific LCA studies. Data and inventories on the structure and efficiency of alternative charging 
systems are particularly needed to compare alternative options such as battery swapping or hybrid electric buses.

In future research, the model developed may also be easily extended to incorporate alternative fuels such as first and second generation biofuels for conventional internal combustion engines, or even hydrogen to drive fuel cells; the only limitations being the model size and complexity, and computational times depending on bus network sizes. Based on the outcomes of the current analysis, which considered emission reduction targets separately, incorporating the model into a wider, multicriteria or multi-objective framework would be an interesting direction for future research.

Acknowledgements We are grateful to the technical and management staff at APT Gorizia SpA, particularly to ing. Salateo and ing. Bassanese, for sharing information and for fruitful collaboration at the time of research.

Funding Open access funding provided by Università degli Studi di Udine within the CRUI-CARE Agreement. We gratefully acknowledge the financial support of A2A Energiefuture SpA in the form of a one year research grant to Ms. Caterina Mauro.

\section{Declaration}

Conflict of interest The authors declare that they have no conflict of interest.

Open Access This article is licensed under a Creative Commons Attribution 4.0 International License, which permits use, sharing, adaptation, distribution and reproduction in any medium or format, as long as you give appropriate credit to the original author(s) and the source, provide a link to the Creative Commons licence, and indicate if changes were made. The images or other third party material in this article are included in the article's Creative Commons licence, unless indicated otherwise in a credit line to the material. If material is not included in the article's Creative Commons licence and your intended use is not permitted by statutory regulation or exceeds the permitted use, you will need to obtain permission directly from the copyright holder. To view a copy of this licence, visit http://creativecommons.org/licen ses/by/4.0/.

\section{References}

Adhami AY, Ahmad F (2020) Interactive Pythagorean-hesitant fuzzy computational algorithm for multiobjective transportation problem under uncertainty. Int J Manag Sci Eng Manag 15(4):288-297. https://doi.org/10.1080/17509653.2020.1783381

Ally J, Pryor T (2016) Life cycle costing of diesel, natural gas, hybrid and hydrogen fuel cell bus systems: an Australian case study. Energy Policy 94:285-294. https://doi.org/10.1016/j.enpol.2016.03.039

APT (2017) Data collection of actual transit bus system in Monfalcone. Personal communication, 24 July 2017

Arteconi A, Polonara F (2013) LNG as vehicle fuel and the problem of supply: the Italian case study. Energy Policy 62:503-512. https://doi.org/10.1016/j.enpol.2013.08.01

Bakker S, Konings R (2018) The transition to zero-emission buses in public transport: the need for institutional innovation. Trans Res D Transp Environ 64:204-215

Buakum D, Wisittipanich W (2020) Stochastic internal task scheduling in cross docking using chanceconstrained programming. Int J Manag Sci Eng Manag 15(4):258-264. https://doi.org/10.1080/ 17509653.2020.1764404

Büyüközkan G, Feyzioğlu O, Göçer F (2018) Selection of sustainable urban transportation alternatives using an integrated intuitionistic fuzzy Choquet integral approach. Trans Res D Transp Environ 58:186-207 
California Air Resources Board (2016) Advanced clean transit battery cost for heavy-duty electric vehicles. https://ww3.arb.ca.gov/msprog/bus/battery_cost.pdf. Accessed 9 Aug 2020

Camerano S, Perretti ME, Dell'Aquila C, Screpanti S, Proia E, Nicotera A, Meko E, Usai V (2017) Investire nel trasporto pubblico. Mezzi e reti per la mobilità. Cassa Depositi e Prestiti, ASSTRA Associazione Trasporto Pubblico. https://www.ferpress.it/wp-content/uploads/2017/01/il-Quadernodella-CdP-Investire-nel-Trasporto-Pubblico.pdf. Accessed 5 Feb 2021

Chen Z, Yin Y, Song Z (2018) A cost-competitiveness analysis of charging infrastructure for electric bus operations. Trans Res c: Emerg 93:351-366

Chinese D, Patrizio P, Bonotto M (2014) A service station location model to explore prospects and policies for alternative transport fuels: a case of CNG distribution in Italy. In: de Sousa J, Rossi R (eds) Computer-based modelling and optimization in transportation, advances in intelligent systems and computing, vol 262. Springer, Cham. https://doi.org/10.1007/978-3-319-04630-3_6

Chinese D, Santin M, Saro O (2017) Water-energy and GHG nexus assessment of alternative heat recovery options in industry: a case study on electric steelmaking in Europe. Energy 141:2670-2687

CIVITAS Policy Note, Smart choices for cities: Alternative Fuel Buses (2016) http://civitas.eu/sites/ default/files/civ_pol-08_m_web.pdf. Accessed 6 Aug 2020

Corazza MV, Guida U, Musso A, Tozzi M (2016) A European vision for more environmentally friendly buses. Trans Res D Transp Environ 45:48-63

Correa G, Muñoz P, Falaguerra T, Rodriguez CR (2017) Performance comparison of conventional, hybrid, hydrogen and electric urban buses using well to wheel analysis. Energy 141:537-554

DIRECTIVE 2009/28/EC OF THE EUROPEAN PARLIAMENT AND OF THE COUNCIL of 23 April 2009 on the promotion of the use of energy from renewable sources (2009) https://eur-lex.europa. eu/LexUriServ/LexUriServ.do?uri=OJ:L:2009:140:0016:0062:en:PDF. Accessed 9 Aug 2020

Donateo T, Licci F, D'Elia A, Colangelo G, Laforgia D, Ciancarelli F (2015) Evaluation of emissions of $\mathrm{CO}_{2}$ and air pollutants from electric vehicles in Italian cities. Appl Energy 157:675-687

Durango-Cohen PL, McKenzie EC (2018) Trading off costs, environmental impact, and levels of service in the optimal design of transit bus fleets. Trans Res A Pol 114:354-363

European Commission (EC) (2017) Better regulation toolbox. https://ec.europa.eu/info/sites/info/files/ better-regulation-toolbox.pdf. Accessed 9 Aug 2020

Ebusplan - Solutions for Clean Transportation, LCC calculator (2018) Parameter for electric buses: code example. http://ebuslcc.ebusplan.com/en/calculator/example/elektrobus/. Accessed 10 Mar 2018

Edwards R, Larivé, JF, Beziat J (2011) Well-to-wheels analysis of future automotive fuels and powertrains in the European context. JRC, CONCAWE and Renault/EUCAR, 74. http://www.optiresour ce.org/prova/pdf/JRC_Eucar/wtw3_wtt_report_eurformat.pdf. Accessed 9 Aug 2020

Emiliana Serbatoi (2017) Sistemi di erogazione: FIMAC stradale, Personal communication

Ercan T, Tatari O (2015) A hybrid life cycle assessment of public transportation buses with alternative fuel options. Int J Life Cycle Assess 20(9):1213-1231

Ercan T, Zhao Y, Tatari O, Pazour JA (2015) Optimization of transit bus fleet's life cycle assessment impacts with alternative fuel options. Energy 93(1):323-334. https://doi.org/10.1016/j.energy.2015. 09.018

Environmental Systems Research Institute (ESRI) (2017) ArcGIS Desktop: Release 10.5.1. Redlands, CA

Esser A, Eichenlaub T, Schleiffer JE et al (2020) Comparative evaluation of powertrain concepts through an eco-impact optimization framework with real driving data. Optim Eng. https://doi.org/10.1007/ s11081-020-09539-2

Galileo Technologies (2020) Distributori di metano per autotrazione CNG/Bio-CNG. https://www.galil eoar.com/it/distributori-di-metano-per-autotrazione-emb/. Accessed 9 Aug 2020

GTT (2017) Bus fleet technical Fact Sheet. http://www.gtt.to.it/cms/risorse/gruppo/veicoli/parco_veicoli_ tpl.pdf. Accessed 9 Aug 2020

Gustafsson M, Svensson N, Anderberg S (2018) Energy performance indicators as policy support for public bus transport: the case of Sweden. Trans Res D Transp Environ 65:697-709

Harris A, Soban D, Smyth BM, Best R (2018) Assessing life cycle impacts and the risk and uncertainty of alternative bus technologies. Renew Sustain Energy Rev 97:569-579

Harris A, Soban D, Smyth BM, Best R (2020) A probabilistic fleet analysis for energy consumption, life cycle cost and greenhouse gas emissions modelling of bus technologies. Appl Energ 261:114422

He Y, Song Z, Liu Z (2019) Fast-charging station deployment for battery electric bus systems considering electricity demand charges. Sustain Cities Soc 48:101530

Hellgren J (2007) Life cycle cost analysis of a car, a city bus and an intercity bus powertrain for year 2005 and 2020. Energy Policy 35(1):39-49. https://doi.org/10.1016/j.enpol.2005.10.004 
Islam A, Lownes N (2019) When to go electric? A parallel bus fleet replacement study. Transp Res Part D Transp Environ 72:299-311. https://doi.org/10.1016/j.trd.2019.05.007

ISPRA (2014) Rete del Sistema Informativo Nazionale Ambientale: La banca dati dei fattori di emissione medi del trasporto stradale in Italia. http://www.sinanet.isprambiente.it/it/sia-ispra/fetransp/. Accessed 9 Aug 2020

Kampman N, Verbeek R, van Grinsven A, van Mensch P, Croezen H, Patuleia A (2013) Bringing biofuels on the market: options to increase EU biofuels volumes beyond the current blending limits. Report Delft, CE Delft Pubbl, July 2013. https://ec.europa.eu/energy/sites/ener/files/documents/ 2013_11_bringing_biofuels_on_the_market.pdf. Accessed 9 Aug 2020

Khan IM, Yasmin T, Shakoor A (2015) Technical overview of compressed natural gas (CNG) as a transportation fuel. Renew Sustain Energy Rev 51:785-797. https://doi.org/10.1016/j.rser.2015.06.053

Khandekar A, Rajagopal D, Abhyankar N, Deorah S, Phadke A (2018) The case for all new city buses in India to be electric. https://escholarship.org/uc/item/7d64m1cd. Accessed 9 Aug 2020

Kunith A, Mendelevitch R, Goehlich D (2017) Electrification of a city bus network: an optimization model for cost-effective placing of charging infrastructure and battery sizing of fast charging electric bus systems. Int J Sustain Transp 11(10):707

Lajunen A (2014) Energy consumption and cost-benefit analysis of hybrid and electric city buses. Trans Res C Emerg 38:1-15

Lajunen A, Lipman T (2016) Lifecycle cost assessment and carbon dioxide emissions of diesel, natural gas, hybrid electric, fuel cell hybrid and electric transit buses. Energy 106:329-342

Lee JY, Cha KH, Lim TW, Hur T (2011) Eco-efficiency of H2 and fuel cell buses. Int J Hydrog Energy 36(2):1754-1765. https://doi.org/10.1016/j.ijhydene.2010.10.074

Lindgren L (2015) Full electrification of Lund city bus traffic: a simulation study. http://portal.research. lu.se/portal/en/publications/full-electrification-of-lund-city-bus-traffic--a-simulation-study(e2be3 892-c749-403f-9363-59bb44a961a7).html\#Overview. Accessed 9 Aug 2020

Logan KG, Nelson JD, Hastings A (2020) Electric and hydrogen buses: shifting from conventionally fuelled cars in the UK. Trans Res D Transp Environ 85:102350

Mahmoud M, Garnett R, Ferguson M, Kanaroglou P (2016) Electric buses: a review of alternative powertrains. Renew Sustain Energy Rev 62:673-684. https://doi.org/10.1016/j.rser.2016.05.019

Mandova H, Patrizio P, Leduc S, Kjärstad J, Wang C, Wetterlund E, Gale W (2019) Achieving carbonneutral iron and steelmaking in Europe through the deployment of bioenergy with carbon capture and storage. J Clean Prod 218:118-129

Marcantonini C, Ellerman AD (2015) The implicit carbon price of renewable energy incentives in Germany. Energy J 36(4):205-239. https://doi.org/10.5547/01956574.36.4.cmar

MARCON (2016) Electric bus feasibility study for the city of Edmonton. https://www.edmonton.ca/ documents/transit/ETS_Electric_Feasibility_Study.pdf. Accessed 9 Aug 2020

McCarl B, Meeraus A, Eijk P, Bussieck M, Dirkse S, Steac P (2008) Expanded Gams User Guide Version 22.9

Mercuri R, Bauen A, Hart D (2002) Options for refuelling hydrogen fuel cell vehicles in Italy. J Power Sources 106(1-2):353-363

Mitropoulos L, Prevedouros PD, Kopelias P (2017) Total cost of ownership and externalities of conventional, hybrid and electric vehicle. Transp Res Procedia 24:267-274

Moro A, Helmers E (2017) A new hybrid method for reducing the gap between WTW and LCA in the carbon footprint assessment of electric vehicles. Int J Life Cycle Assess 22:4-14. https://doi.org/10. 1007/s11367-015-0954-z

Nie Y, Ghamami M, Zockaie A, Xiao F (2016) Optimization of incentive policies for plug-in electric vehicles. Trans Res B Methods 84:103-123

Noel L, Zarazua de Rubens G, Sovacool BK, Kester J (2019) Fear and loathing of electric vehicles: the reactionary rhetoric of range anxiety. Energy Res Soc Sci 48:96-107. https://doi.org/10.1016/j.erss. 2018.10.001

Nylund NO, Koponen K (2012) Fuel and technology alternatives for buses: overall energy efficiency and emission. VTT Technol 46. http://www.vtt.fi/inf/pdf/technology/2012/T46.pdf. Accessed 9 Aug 2020

Nylund N (2014) Real performance of buses. In: NTM Annu. Memb. Meet. 2014 Increasing Credibil. Transp. Environ. Perform., VTT Technical Research Centre of Finland. https://www.transportm easures.org/wp-content/uploads/2014/07/NTM_Nylund_290414.pdf. Accessed 9 Aug 2020

Patel PD, Lakdawala A, Chourasia S, Patel RN (2016) Bio fuels for compression ignition engine: a review on engine performance, emission and life cycle analysis. Renew Sustain Energy Rev 65:24-43 
Patrizio P, Chinese D (2016) The impact of regional factors and new bio-methane incentive schemes on the structure, profitability and $\mathrm{CO}_{2}$ balance of biogas plants in Italy. Renew Energy 99:573-583

Pereirinha PG, González M, Carrilero I, Anseán D, Alonso J, Viera JC (2018) Main trends and challenges in road transportation electrification. Transp Res Proc 33:235-242

Petrauskienė K, Skvarnavičiūtė M, Dvarionienė J (2020) Comparative environmental life cycle assessment of electric and conventional vehicles in Lithuania. J Clean Prod 246:119042

Pihlatie M, Kukkonen S, Halmeaho T, Karvonen V, Nylund NO (2014) Fully electric city buses-the viable option. IEEE Int. Electr. Veh. Conf. IEVC 2014, 17 - 19 December 2014, Florence, Italy. https://doi.org/ 10.1109/IEVC.2014.7056145

Rogge M, Wollny S, Sauer DU (2015) Fast charging battery buses for the electrification of urban public transport-a feasibility study focusing on charging infrastructure and energy storage requirements. Energies 8(5):4587-4606. https://doi.org/10.3390/en8054587

Rogge M, Van Der Hurk E, Larsen A, Sauer DU (2018) Electric bus fleet size and mix problem with optimization of charging infrastructure. Appl Energy 211:282-295. https://doi.org/10.1016/j.apenergy.2017.11.051

Rothgang S, Rogge M, Becker J, Sauer DU (2015) Battery design for successful electrification in public transport. Energies 8:6715-6737

Sen B, Ercan T, Tatari O (2017) Does a battery-electric truck make a difference? Life cycle emissions, costs, and externality analysis of alternative fuel-powered Class 8 heavy-duty trucks in the United States. J Clean Prod 141:110-121

Shen ZJM, Feng B, Mao C, Ran L (2019) Optimization models for electric vehicle service operations: a literature review. Trans Res B Methods 128:462-477

Sinhuber P, Rohlfs W, Sauer DU (2012) Study on power and energy demand for sizing the energy storage systems for electrified local public transport buses. In: 2012 IEEE vehicle power and propulsion conference, Seoul, South Korea. https://doi.org/10.1109/VPPC.2012.6422680

Su Y, Liu X, Lu G, Fan W (2019) Optimal design of bus routes for different vehicle types considering various driving regimes and environmental factors. Transp Res Rec 2673:299-316. https://doi.org/10.1177/03611 98119841566

Transport and Environment (2019) Emission Reduction Strategies for the Transport Sector in Italy. https://www. transportenvironment.org/publications/emissions-reduction-strategies-transport-sector-italy. Accessed 5 Feb 2021

Tzeng GH, Lin CW, Opricovic S (2005) Multi-criteria analysis of alternative-fuel buses for public transportation. Energy Policy 33(11):1373-1383

UITP (2016) Statistics in brief. https://www.uitp.org/sites/default/files/cck-focus-papers-files/UITP_Statistics_ PT_in_EU_DEF_0.pdf. Accessed 9 Aug 2020

UITP (2018) Decarbonization. https://www.uitp.org/sites/default/files/Decarbonisation\%20-\%20the\%20public\% 20transport\%20contribution.pdf. Accessed 9 Aug 2020

Wang MQ (2001) Development and use of GREET 1.6 fuel-cycle model for transportation fuels and vehicle technologies (No. ANL/ESD/TM-163). Argonne National Lab., IL (US)

Wang M (2002) Fuel choices for fuel-cell vehicles: well-to-wheels energy and emission impacts. J Power Sources 112(1):307-321

Wang Y, Huang Y, Xu J, Barclay N (2017) Optimal recharging scheduling for urban electric buses: a case study in Davis. Trans Res E Log 100:115-132

William HP (2003) Model building in mathematical programming. Wiley, Hoboken

Xylia M, Leduc S, Patrizio P, Kraxner F, Silveira S (2017) Locating charging infrastructure for electric buses in Stockholm. Trans Res C Emerg 78:183-200

Xylia M, Leduc S, Laurent A, Patrizio P, Der Meer V, Kraxner F, Silveira S (2019) Impact of bus electrification on carbon emissions: the case of Stockholm. J Clean Prod 209:74-87

Zhang Y, Hua QS, Li S, Qie L (2020) Life cycle optimization of renewable energy systems configuration with hybrid battery/hydrogen storage: a comparative study. J Energy Storage 30:101470. https://doi. org/10.1016/j.est.2020.101470

Zhou B, Wu Y, Zhou B, Wang R, Ke W, Zhang S, Hao J (2016) Real-world performance of battery electric buses and their life-cycle benefits with respect to energy consumption and carbon dioxide emissions. Energy 96:603-613. https://doi.org/10.1016/j.energy.2015.12.041

Publisher's Note Springer Nature remains neutral with regard to jurisdictional claims in published maps and institutional affiliations. 